\title{
Amide Activation in Ground and Excited States
}

\author{
Ervin Kovács ${ }^{1}{ }^{\mathbb{D}}$, Balázs Rózsa ${ }^{2}$, Attila Csomos ${ }^{3}$, Imre G. Csizmadia ${ }^{4}$ and Zoltán Mucsi ${ }^{4,5, *}$ \\ 1 Institute of Materials and Environmental Chemistry, Research Centre for Natural Sciences, \\ Hungarian Academy of Sciences, Budapest H-1117, Hungary; kovacs.ervin@ttk.mta.hu \\ 2 Laboratory of 3D Functional Imaging of Neuronal Networks and Dendritic Integration, Institute of \\ Experimental Medicine, Hungarian Academy of Sciences, Budapest H-1083, Hungary; rozsabal@koki.hu \\ 3 Institute of Chemistry, Eötvös University, Budapest H-1117, Hungary; csomosattila@caesar.elte.hu \\ 4 Department of Chemistry, University of Toronto, Toronto, ON M5S 3H6, Canada; icsizmad@hotmail.com \\ 5 Department of Chemistry, Femtonics Inc., Budapest H-1094, Hungary \\ * Correspondence: zoltanmucsi@gmail.com or zmucsi@femtonics.eu; Tel.: +36-20-441-6971
}

Academic Editor: Michal Szostak

Received: 4 October 2018; Accepted: 31 October 2018; Published: 2 November 2018

\begin{abstract}
Not all amide bonds are created equally. The purpose of the present paper is the reinterpretation of the amide group by means of two concepts: amidicity and carbonylicity. These concepts are meant to provide a new viewpoint in defining the stability and reactivity of amides. With the help of simple quantum-chemical calculations, practicing chemists can easily predict the outcome of a desired process. The main benefit of the concepts is their simplicity. They provide intuitive, but quasi-thermodynamic data, making them a practical rule of thumb for routine use. In the current paper we demonstrate the performance of our methods to describe the chemical character of an amide bond strength and the way of its activation methods. Examples include transamidation, acyl transfer and amide reductions. Also, the method is highly capable for simple interpretation of mechanisms for biological processes, such as protein splicing and drug mechanisms. Finally, we demonstrate how these methods can provide information about photo-activation of amides, through the examples of two caged neurotransmitter derivatives.
\end{abstract}

Keywords: amide; activation; amidicity; carbonylicity; transamidation; acyl transfer; excited state

\section{Introduction}

The amide functional group is one of the most generally used moieties both in synthetic organic chemistry and bioorganic chemistry [1-5]. They have been known and studied for more than a century and can be commonly found in peptides/proteins and biologically active compounds, as well as in a broad range of synthetic drugs and toxins as a key functionality [1,6-9]. In general, when speaking of amides, the idea of a stable, unreactive group comes in our minds, however, they can play a significant role as reactants in a vast number of processes.

The wide variability in their reactivity can be attributed to the possibility of fine-tuning the bond strength. This can be controlled by attached substituent groups at the carbon and nitrogen atoms. The correlation between poor reactivity and planarity $[10,11]$ of amides was proposed firstly by Pauling and later it was understood as being a result of the strength of the resonance-stabilized amide C-N bond [12]. Pauling predicted that a typical planar amide exhibits approximately $40 \%$ partial double-bond character, which renders the amide bond one of the most solid and least reactive functional groups (Figure 1) $[13,14]$. For example, the conjugation of an amide bond, which is traditionally specified as $\mathrm{n}(\mathrm{N}) \rightarrow \pi^{*}(\mathrm{C}=\mathrm{O})$, in formamide results in resonance energy (RE) of $91.29 \mathrm{kcal} \mathrm{mol}^{-1}[15,16]$. In contrast to that, embedding the amide bond into a rigid bicyclic frame with nitrogen at the ring fusion, significantly modifies the degree of the resonance, therefore increasing the instability of the strained amide bond, for example in $\beta$-lactam antibiotics [17-19]. More intense conjugation implies a 
larger contribution of resonance stabilization, which increases the system stability thus lowering the reactivity and vice versa. In other words, the extent of conjugation predetermines chemical reactivity of the amides [20].

Amides can readily be cleaved by enzymes such as protease $[15,16]$, but synthetically it is difficult to selectively break the carbon-nitrogen bond [21-31]. How can nature solve a problem easily, that is so hard for us? The answer is hidden in the process of activation of the unreactive group.

Organic chemists and "Nature" have developed methods to activate stable amide bonds, to make possible various reactions. Numerous examples of these can be found in the field of synthetic organic chemistry and biochemistry. The amide activation is typically based on the lowering of the amidic character by forcing the amide group to lose its conjugation. This can be achieved by substituent groups, as well as by forcing them into an inflexible structure. Moreover, as Thakkar et al. have described, the presence of the cis or trans isomer in the planar character of the amide bond in stable geometries can also influence the overall reactivity [32]. In connection with special chromophores, amide bonds can also be activated under excitation, as was demonstrated in some earlier studies [33-35]. Some of these processes include amidation, transamidation, reduction, coupling reactions by transition metallic complexes, and spontaneous or enzymatic hydrolysis.

The aim of our paper is to characterize the activity of amides using the amidicity and carbonylicity concepts and to demonstrate possibilities to increase or decrease their activity based on the bond strength [14]. In this work, using quantum chemical computation by using Gaussian 09 [36] at B3LYP /6-31G(d,p) level of theory [37], we reevaluated the data reported in the literature for reactivity of amide bonds. Here we reinterpreted some selected well-known compounds and reactions using the simple rule of amidicity, which can estimate the direction and rate of similar reactions involving more complex reactants.

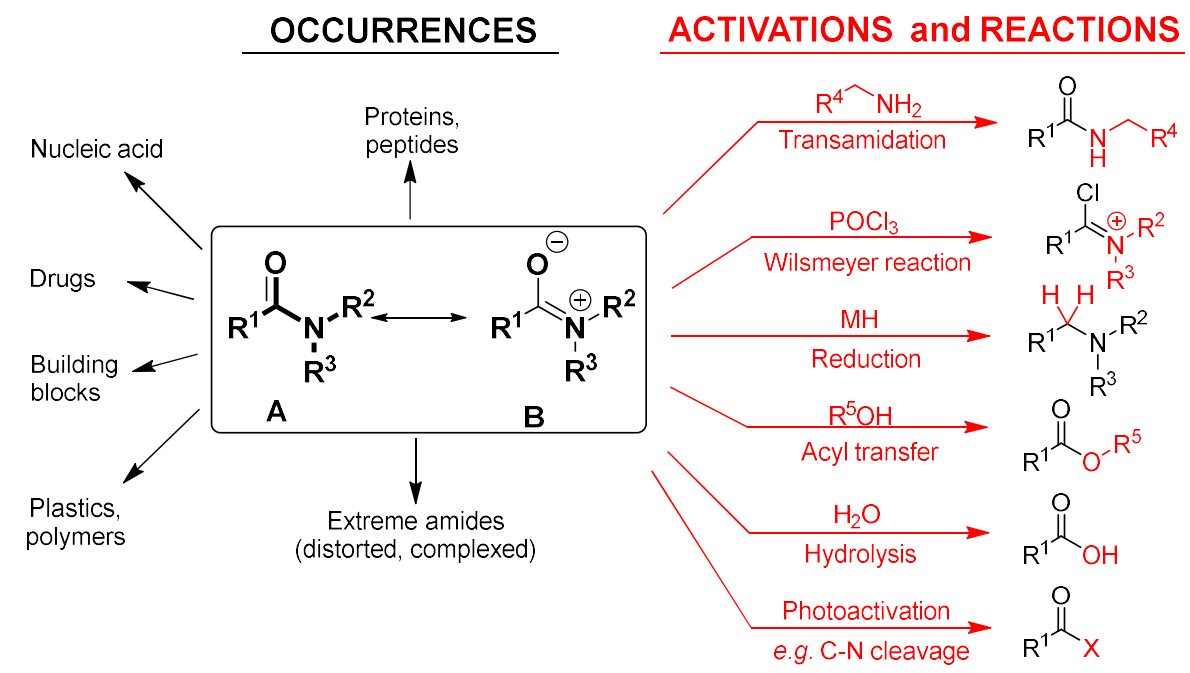

Figure 1. Contributing resonance structures of an amide bond (in the box). The occurrences (left) of the amide functionality and their typical reactions (right).

\section{Discussion}

The amide group can be described generally by its resonance structures (A and B in Figure 1), where the nitrogen lone electron pair is delocalized between the nitrogen and the neighboring carbonyl. The condition of this phenomenon is a planar structure of the amide group. For the resonance structure B (Figure 1), the nucleophilic attack to the group is far less possible, thus making a general amide a resistant and unreactive group. The chemical and biochemical stability and reactivity is determined by the contribution of the minor resonance structure (B in Figure 1), in which formally a double bond is formed between the carbon and nitrogen atoms. These characteristics can be represented on a wide spectrum. 
Earlier, the strength of a given amide bond was successfully characterized and the reactivity of different amides was made comparable to each other by creating the so called linear "amidicity scale" (Figure 2B) [27]. Analogously, a linear "carbonylicity scale" (Figure 2A) was also constructed, extending the group of amides toward the entire world of carbonyl compounds, making all of them comparable [20]. Other methods, such as carbonyl substitution nitrogen atom replacement $[6,38,39]$ and transamidation (TA) [14] which also aim to measure the amide stabilization energy, were also published in the literature. Using this scale, we are able not only to explain the reactivity of the amide bond, but also predict the effect of different substituents on the bond strength. Predicting amide bond strength effectively gives us the opportunity to activate or reactivate the desired amide bond. Manipulating the amidicity of a selected amide of a molecule has numerous synthetic applications. Also, calculating the amidicity - in other words, estimating the activity of the amide bond in biochemical compounds-may clarify the mechanism of action in which they are involved.

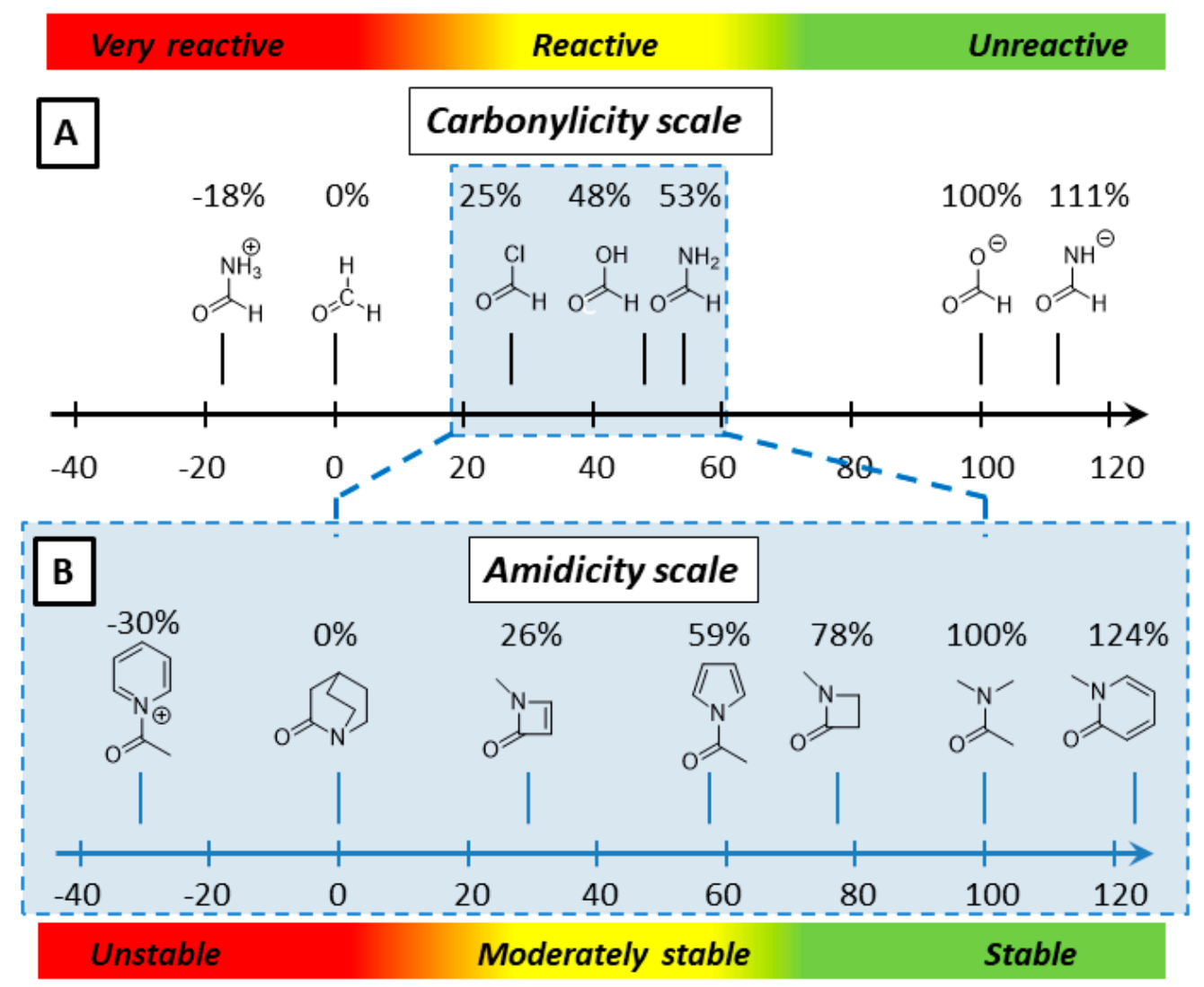

Figure 2. Typical carbonyl and amide compounds represented on the carbonylicity (A) and amidicity (B) scales. The direction of reactivity and stability increase are shown by red and green strips, respectively.

\subsection{Amidicity Scale (AM\%) and Carbonylicity Scale (CA\%) and Their Resonance Enthalpies $\left(H_{R E}\right)$}

The "amidicity scale" [27] quantifies the amide bond strength on a linear scale (Figure 3A), based on the computed enthalpy of hydrogenation $\left(\Delta \mathrm{H}_{\mathrm{H} 2}\right)$ of the examined compound. A few examples positioned on the scale demonstrate the wide variety of amides. The scale is based on two specifically chosen reference compounds: A1 and B1 (Figure 3A). Compound aza-adamantane-2-on (A1 in Figure 3A) represents the lack of amidic charater, while dimethylacetamide (B1 in Figure 3A) corresponds to the perfect amide bond. In the structure of A1, the planar geometry is missing, due to the forced arrangement of the bridged $\mathrm{N}$ atom. To create the amidicity scale (AM\%), the enthalpy of hydrogenation $\left(\Delta \mathrm{H}_{\mathrm{H} 2}\right)$ of compounds $\mathrm{A} 1$ and B1 was calculated Equations (1) and (2) and amidicity was defined using a linear fit to these points. The enthalpy of hydrogenation for $\mathrm{A} 1\left(\Delta \mathrm{H}_{\mathrm{H} 2}[\mathrm{~A}]\right)$ 
is considered to have a $0 \% \mathrm{AM} \%$ value, while that for $\mathrm{B} 1\left(\Delta \mathrm{H}_{\mathrm{H} 2}[\mathrm{~B}]\right)$ is considered to have a $100 \%$ $\mathrm{AM} \%$ value.

$$
\begin{gathered}
\Delta H_{H 2}[\mathrm{~A}]=H[\mathrm{~A} 2]-\left\{H[\mathrm{~A} 1]+H\left[\mathrm{H}_{2}\right]\right\}=-44.62 \mathrm{~kJ} \mathrm{~mol}^{-1} \\
\Delta H_{H_{2}}[\mathrm{~B}]=H[\mathrm{~B} 2]-\left\{H[\mathrm{~B} 1]+H\left(\mathrm{H}_{2}\right)\right\}=34.88 \mathrm{~kJ} \mathrm{~mol}^{-1}
\end{gathered}
$$

As specified before, the carbonylicity scale (CA\%) [20] quantifies the conjugation of the carbonyl group on a linear scale (Figure $3 \mathrm{~B}$ ), based on computed enthalpy of hydrogenation $\left(\Delta \mathrm{H}_{\mathrm{H} 2}\right)$ of the examined carbonyl group (Equations (3) and (4)). Analogously to amidicity, the carbonylicity scale is also based on two specifically chosen reference compounds, $\mathrm{C} 1$ (formaldehyde; $\mathrm{CA} \%=0 \%$ ) and D1 (formate; $\mathrm{CA} \%=100 \%$ ) and defined using a linear fit to these points. Also, note that the amidicity scale is a defined section of the carbonylicity scale as it is represented on Figure 2, and differs only in the reference compunds chosen.
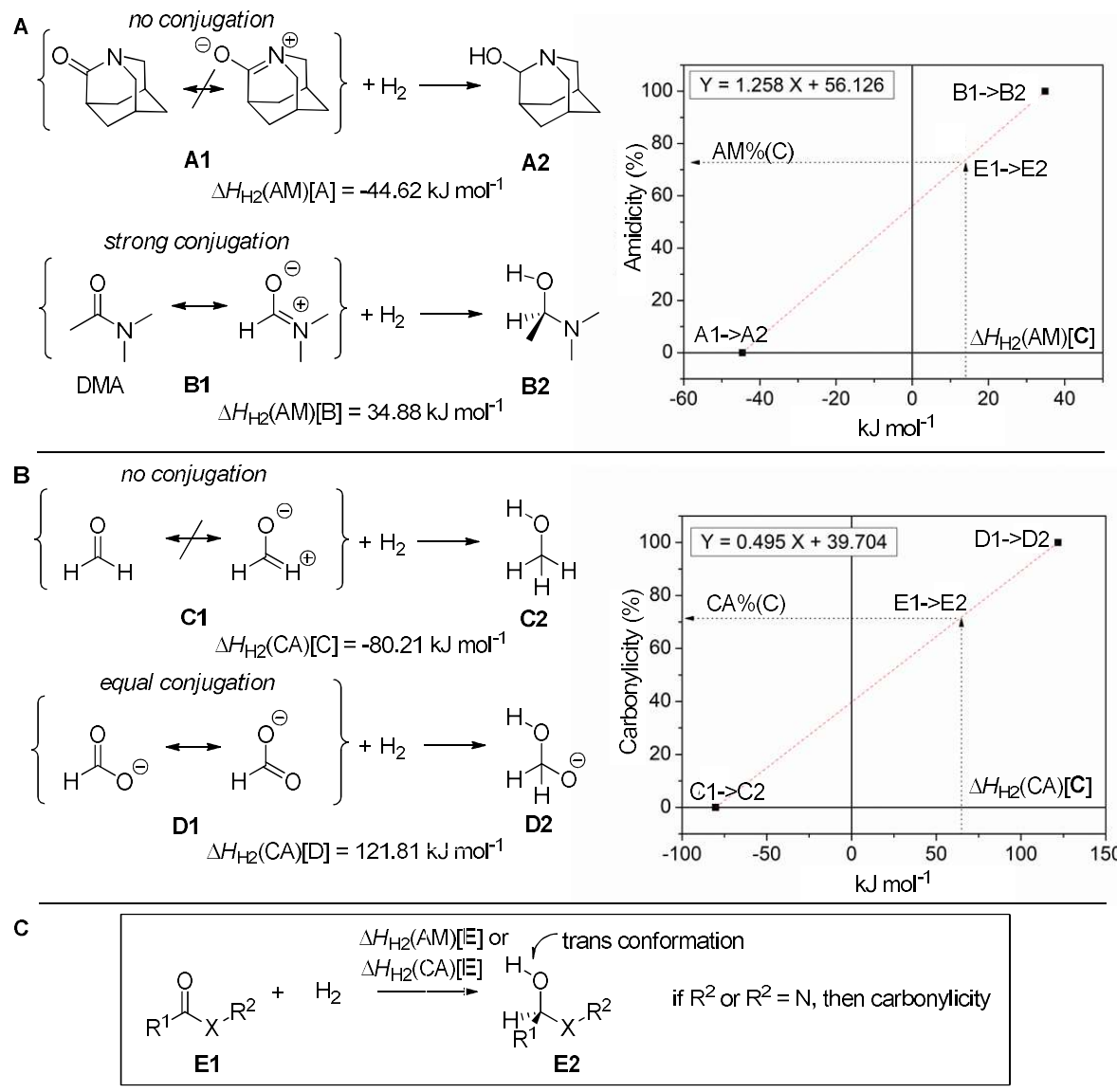

Figure 3. The definition of the amidicity (A) and carbonylicity (B) percentage based on the enthalpy of hydrogenation $\left(\Delta H_{\mathrm{H} 2}\right)$ of the carbonyl group of a general carbonyl compound E1 (C). The two specifically chosen reference structures and their hydrogenation are also illustrated as A1 and B1 for amidicity (AM\%; top) as well as $\mathrm{C} 1$ and $\mathrm{D} 1$ for carbonylicity (CA\%; bottom). Values were obtained from the B3LYP/6-31G $(\mathrm{d}, \mathrm{p})$ geometry-optimized structures. In structure $\mathrm{E} 2$, the $\mathrm{O}-\mathrm{C}-\mathrm{X}-\mathrm{R}_{2}$ and the $\mathrm{H}-\mathrm{O}-\mathrm{C}-\mathrm{X}$ dihedral angles are chosen to be in the anti orientation.

$$
\begin{aligned}
& \Delta H_{\mathrm{H} 2}[\mathrm{C}]=H[\mathrm{C} 2]-\left\{H[\mathrm{C} 1]+H\left(\mathrm{H}_{2}\right)\right\}=-80.21 \mathrm{~kJ} \mathrm{~mol}^{-1} \\
& \Delta H_{\mathrm{H} 2}[\mathrm{D}]=H[\mathrm{D} 2]-\left\{H[\mathrm{D} 1]+H\left(\mathrm{H}_{2}\right)\right\}=121.81 \mathrm{~kJ} \mathrm{~mol}^{-1}
\end{aligned}
$$

The linear fits are described by two pairs of fitting parameters, the slope $\left(\mathrm{m}_{\mathrm{AM}}\right.$ and $\left.\mathrm{m}_{\mathrm{CA}}\right)$ and the intercept $\left(\mathrm{b}_{\mathrm{AM}}\right.$ and $\left.\mathrm{b}_{\mathrm{CA}}\right)$. The values (AM\% and $\mathrm{CA} \%$ ) for a desired amide or carbonyl bond can be easily calculated with the help of Equations (6) and (8), for a known enthalpy of hydrogenation, $\Delta \mathrm{H}_{\mathrm{H} 2}$, 
from Equation (5). Both the amidicity and carbonylicity values can be transformed to the resonance enthalpy $\left(\mathrm{H}_{\mathrm{RE}}[\mathrm{E}]\right.$; Equations (7) and (9)), which helps to estimate the energy benefit coming from the resonance inside the group. Neither of these scales is limited to values between $0 \%$ and $100 \%$; in extreme cases the bond is weaker than A1 or C1 and stronger than B1 or D1, so they may display values outside of the aformentioned range. The amidicity scale can be considered as a sub-section of the carbonylicity scale.

$$
\begin{gathered}
\Delta H_{\mathrm{H} 2}[\mathrm{E}]=H[\mathrm{E} 2]-\left\{H[\mathrm{E} 1]+H\left(\mathrm{H}_{2}\right)\right\} \\
A M \%[\mathrm{E}]=m_{\mathrm{AM}} \Delta H_{\mathrm{H} 2}[\mathrm{E}]+b_{\mathrm{AM}} \\
H_{\mathrm{RE}}[\mathrm{E}]=A M \% / m_{\mathrm{AM}} \\
C A \%[\mathrm{E}]=m_{\mathrm{CA}} \Delta H_{\mathrm{H} 2}[\mathrm{E}]+b_{\mathrm{CA}} \\
H_{\mathrm{RE}}[\mathrm{E}]=C A \% / m_{\mathrm{CA}}
\end{gathered}
$$

\subsection{Transamidation and Transacylation Reactions in Synthetic Organic Chemistry}

The amidicity value is useful to predict the outcome of a general transamidation reaction (Figure 4, top). The amidicity change $\Delta \mathrm{AM}$ in Equation (10) or the change in stabilization enthalpy $\left(\Delta \mathrm{H}_{\mathrm{RE}}\right.$ in Equation 12) leads to a thermodynamic selection rule, allowing for the reactions to be categorized as being either thermodynamically favorable or unfavorable. Generally, $\Delta \mathrm{H}_{\mathrm{RE}}$ is proportional with the entalpy change of the transamidation reaction. The lower the amidicity value of the chosen group, the greater reactivity it has towards nucleophylic reagents, like amines. The direction of the transamidation reactions can be predicted by comparing the sum of amidicities on the product and reactant sides. If the amidicity value increases, the reaction is energetically favoured in the given direction. If the difference is a negative value, the reaction is not driven forward. If there are different possible reaction routes, the one with the greater increase in amidicity is favored. The amidicity value is also capable of predicting the most active amide group in a molecule. Such a thermodynamic selection rule may also be used to predict the selectivity of a reaction in the presence of competing amide functionalities. This principle is illustrated as being operative in cases of different reactions. However, it should be mentioned that reactions may have several other parameters that determine if a reaction can proceed or not, such as steric hinderance, kinetic consequences, side reactions and the role of the leaving group on the acyl group. These amidicity and carbonylicity values describe only the thermodynamic background and not the kinetic aspect of a reaction.

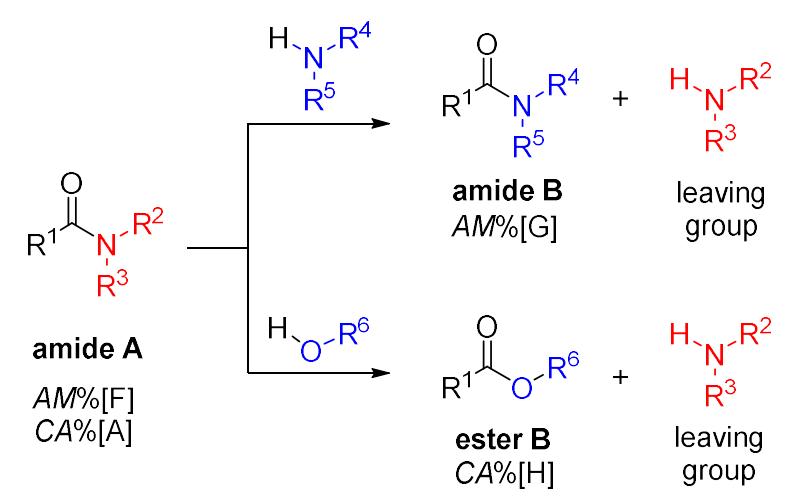

Figure 4. General transamidation reaction and the amidicity (AM\%) and carbonylicity (CA\%) percentages of the amides examined.

$$
\begin{gathered}
\Delta A M=A M \%[\mathrm{G}]-A M \%[\mathrm{~F}] \\
\Delta C A=C A \%[\mathrm{H}]-C A \%[\mathrm{~F}] \\
\Delta H_{\mathrm{TA}} \approx \Delta H_{\mathrm{RE}}=H_{\mathrm{RE}}[\mathrm{B}]-H_{\mathrm{RE}}[\mathrm{A}]
\end{gathered}
$$


On the basis of the exploratory screening of the literature, four cases were defined (Figure 5) [40]. Cases I and II (one-step processes) are both thermodynamically favored yet differ in reaction barrier height. Reaction barriers in case I are low [41], while those of case II are high, with the latter requiring a suitably chosen Lewis acid catalyst $\left(\mathrm{AlCl}_{3}, \mathrm{BF}_{3}, \mathrm{TiCl}_{4}, \mathrm{HCl}\right.$, etc.) to proceed normally [42,43]. This amine exchange reaction is sometimes carried out in a closed autoclave at high temperature by using the salt of the amine in the presence of $\mathrm{BF}_{3}$ [44], often to convert simple urea to a substituted one. In contrast to that, both cases of III and IV (two-step processes) are thermodynamically unfavorable, requiring the activation of either the reacting amide (case III) or the reacting amine. In case III, the amide is effectively destabilized, so activated by nitrosation, nitration, or acylation step [ $N$-activation by activating group (AG), case III, Figure 5]. This activation is manifested as an increase in the energy level of the starting state, wherein the activated amide intermediate provides a thermodynamically favorable and rapid transamidation process.

In case IV ( $N$-deprotonation), a theoretically thermodynamically unfavorable transamidation, which may proceed in the presence of a strong base ( $\mathrm{NaH}$ or $\mathrm{NaOR})$. The product monosubstituted amide forms and stays in its deprotonated form $\left(-\mathrm{CO}-\mathrm{NHR}^{4}\right)$ and the starting amide is disubstituted non-deprotanable (-CO-NR ${ }^{1} \mathrm{R}^{2}$, amide). Therein, the forming amide-anion intermediate is stabilized by the deprotonation. In this case, an originally thermodynamically unfavorable transamidation process involves a thermodynamically favorable reversible subprocess, which finally finishes irreversibly by protonation in the acidic work-up.

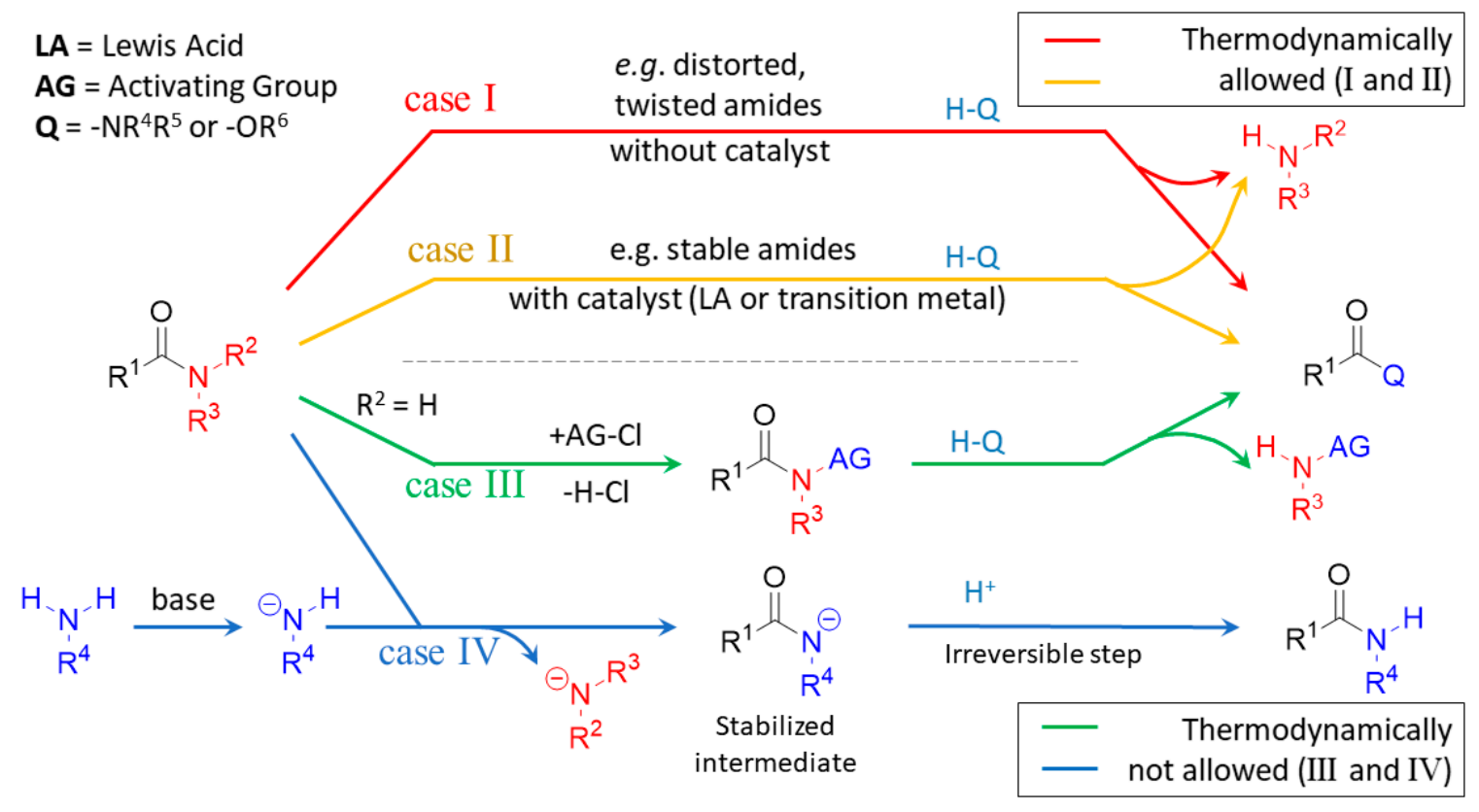

Figure 5. The classification of the acyl transfer and transamidation reactions into four cases (case I, II, III and IV), interpreted by amidicity (AM\%) and carbonylicity (CA\%) values.

2.2.1. Examples of the Thermodynamically Allowed Transamidation Reactions (case I and II)

Transamidation Processes of Simple Amide Compounds

In order to illustrate the essence of the transamidation reaction, we are demonstrating this concept by simple amides and amines. Unsubstituted amides, such as $\mathbf{1}$ and $\mathbf{2}$ in Figure 6, exhibit a moderately reduced value of amidicity (Figure 6) relative to mono-substituted or di-substituted amides, such as 3 and 4 (97-103\%; Figure 6) [40], so one may therefore predict a transamidation process between them. Mono- and di-substituted amines (e.g., dimethylamine) are shown to react readily with formamide (1) at RT $\left(25^{\circ} \mathrm{C}\right)$ or above without any additional activation (case I). However, the transamidation reaction of acetamide (2) required elevated temperature and the presence of $\mathrm{AlCl}_{3}$ as a Lewis acid activator in 
order to attain an acceptable reaction rate (case II). The harsh conditions are explained by the high activation energy of the sterically hindered reaction center [40].

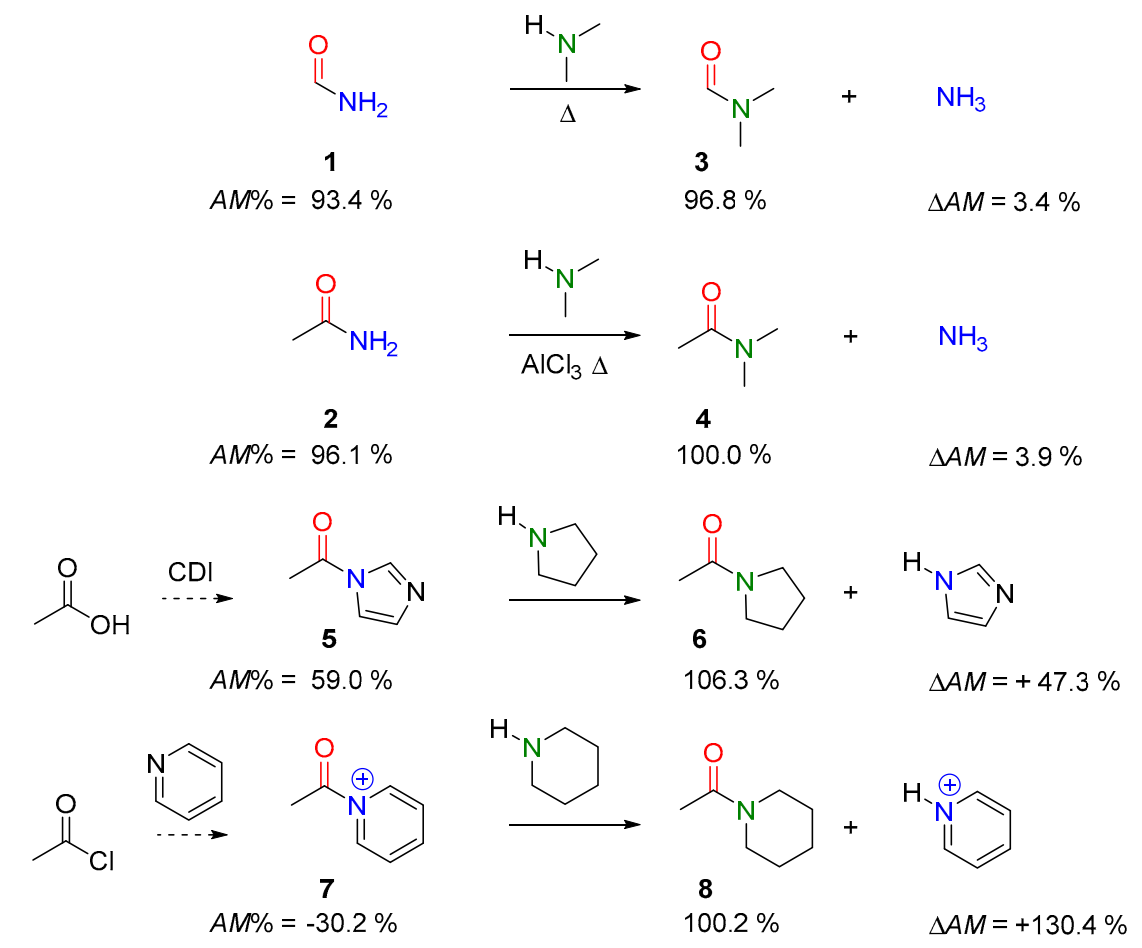

Figure 6. Examples for transamidation involving secondary amine, with the corresponding amidicity values computed at B3LYP/6-31G(d,p) level of theory.

Compound 5 represents mild acylating agents (Figure 6) taking part readily in transamidation reactions with amines (e.g., pyrrolidine), forming amide 6 beside imidazole as a side-product. The synthesis of $\mathbf{5}$ can be carried out simply by means of the corresponding acid and carbonyl diimidazole (CDI) reagent. The increased acylating potency $(\mathrm{AM} \%=59 \%)$ of 5 can be attributed to the competition for the $\mathrm{N}$ atom lone pair between the imidazole aromatic ring and the carbonyl group of the amide. This phenomenon decreases the amidicity percentage of 5 to a value as low as $59 \%$ compared to normal amides. During the acylation reaction $\mathbf{5} \rightarrow \mathbf{6}$, the amidicity value increased significantly, providing the main driving force for this transamidation reaction. Compound 7 (Figure 6) exhibits an extremely low amidicity percentage $(-30.2 \%)$, making this molecule an excellent acylating agent, which can be prepared in situ from $\mathrm{AcCl}$ and pyridine. Consequently, 7 readily furnishes the acylation with an amine (e.g., piperidine), resulting in product 8 . Here, the reaction is motivated by the extremely large change in amidicity $(\triangle \mathrm{AM}$, Figure 6) even at low temperature $[24,31,40,45]$.

Amidicity value is also able to explain the inactivity and resistance of some commonly used organic amide solvents, For example, $\mathrm{N}, \mathrm{N}$-dimethylformamide $(\mathrm{DMF}, \mathrm{AM} \%=100 \%$ ) and $\mathrm{N}$-methylpyrrolidinone (NMP, AM\% $=136 \%$ ) exhibit extremely high amidicity values.

When dissolving any amine in these species, no reaction occurs between them due to the negative $\triangle \mathrm{AM}$, which makes them unfavorable for taking part in any reaction even at high temperature $[24,31,40,45]$.

Transamidation and Acyl Transfer Processes of N-Phenylamides.

In the literature, there are numerous examples where acylated $N$-alkyl anilines are reacted by amines or alcohols in the presence of transition metal catalysts (Pd, Ni, etc.). In these cases, the $N$-alky-anilids exhibit moderately low amidicity values, due to the dual effect of the phenyl ring. The phenyl ring suffers some steric hindrance and competes with the non-bonding electron-pair of 
the $\mathrm{N}$ atom against the acyl group at ones. In retrospect, it appears that the transamidation and acyl transfer reaction can occur without any catalyst, although, in the literature at different times, both of these types of reactions were reported as new approaches. Initially, these were reported to proceed without catalyst in the 1960's [46-49]. However, analogue reactions were highlighted later as a novel approach in the presence of Ni or Pd catalysts. Authors called these reactions new, cross-coupling reactions of $N$-Ar amides (anilides), as reported by Garg et al. [50]. The reactivity of theses aromatic amides, under Ni-catalyzed esterification (Ni/SIPr) was rationalized by the concept of so called "barrier-free" rotation around the N-CO bond [51]. Analogues transacylation reaction with alcohol in the presence of Pd catalyst was also reported [52]. However, the earlier metal or catalyst-free transamidation solutions have subsequently been reinvestigated and rereported as new results [53]. This apparent confusion can be easily resolved by comparing the difference of amidicity values between the aromatic amides (anilids) with aliphatic amides, which thermodynamically allows such transamidation or acyl transfer reaction.

A simple, but illustrative example can be found in the literature, which describes an intramolecular transamidation, where two amine-anilides $(\mathbf{9 , 1 1})$ rearrange to aniline-alkyl-amide products $(\mathbf{1 0 , 1 2}$; in Figure 7) without any catalyst. The positive changes in amidicity values as well as the exothermic enthalpy changes undoubtedly prove the efficiency of these reactions $[46,54,55]$. Other creative synthetic applications, taking advantage of the $N$-phenyl-acyl activation, were also developed for the synthesis of large lactams [53].

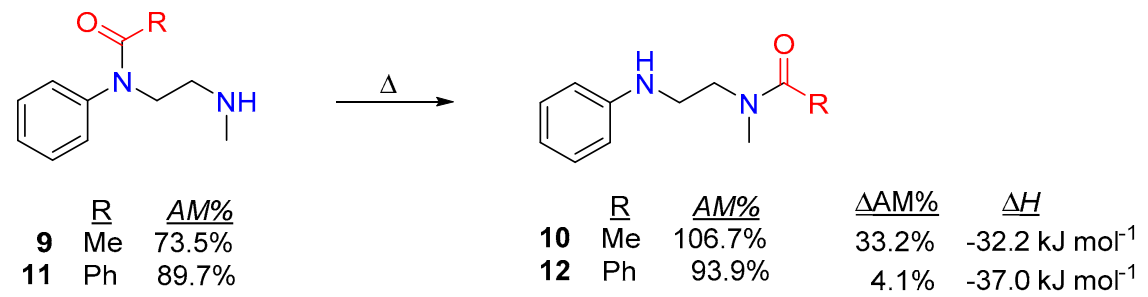

Figure 7. Typical example of intramolecular transamidation rearrangement, with the corresponding amidicity values $(\mathrm{AM} \%)$ as well as amidicity $(\triangle \mathrm{AM})$ and enthalpy change $(\Delta \mathrm{H})$, computed at B3LYP /6-31G(d,p) level of theory.

Acyl Transfer Reactions of Distorted or Twisted Amides

The structural distortion of an amide bond significantly modulates the degree of the amidic resonance, typically by lowering its amidicity/carbonylicity value [56,57]. The two classic twisted bridged lactams (aza-bicycloheptanone 13 [17], penicillin scaffold-penam 14 [58-60]) were synthetized more than 75 years ago. More than six decades later, this was followed by the preparation of 15 (in 1998) and its aromatic derivatives [61-64]. The aza-adamantane analogue 16 (in 2006 [65]), as well its substituted derivatives [66-68] made the series complete. These compounds furnish fully perpendicular arrangement within the amide bonds, resulting in high reactivity similar to that of ketones (Figure 8).

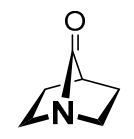

13

$10 \%$
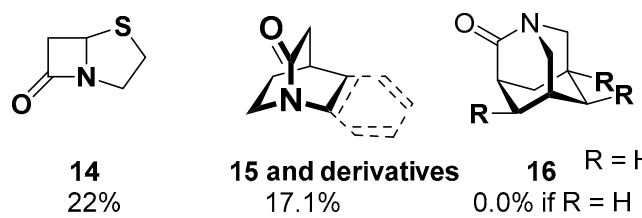

15 and derivatives $\quad 16 \mathrm{R}=\mathrm{H}, \mathrm{Me}$

$17.1 \% \quad 0.0 \%$ if $\mathrm{R}=\mathrm{H}$

(by definition)

Figure 8. Typical examples of synthetized twisted amides (13-16) with the corresponding amidicity computed at B3LYP/6-31G(d,p) level of theory.

At first, we should clarify the difference between the distorted and twisted amides (Figure 9). Updating a previous nomenclature $[6,69]$, the distorted amides reflect some steric hindrance or ring 
strain in their entire structures, but they already possess significant conjugation, with mentionable amidicity values. Here the amides are almost planar. In contrast, twisted amides may be described by a near perpendicular amine plane to the carbonyl plane with pyramidalized $\mathrm{N}$ atom, where the whole structure itself is not distorted or hindered (Figure 9).

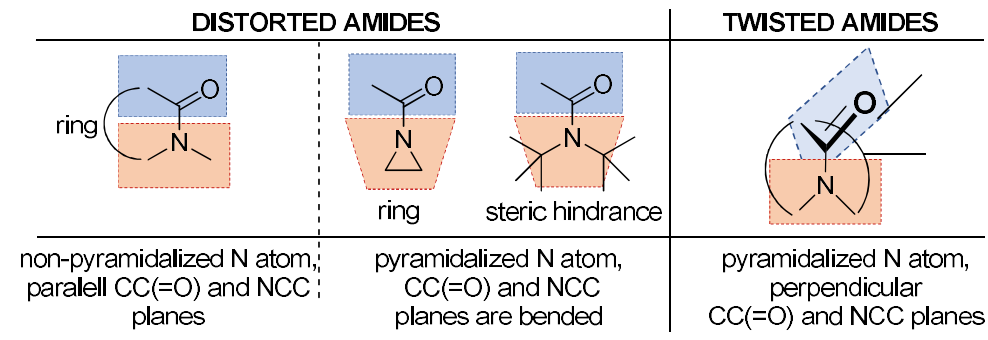

Figure 9. Redefined difference between the distorted and twisted amides. Distorted amides suffer steric hindrance or ring stress with pyramidalized or non-pyramidalized $\mathrm{N}$ atom. Twisted amides do not exhibit any strain, with perpendicular, non-overlapping amide planes. The carbonyl and amide planes are illustrated by the parallel- or perpendicularly-oriented blue and orange colors.

Recently, twisted and distorted amide bonds have slowly found real application as a potent reagent in the mainstream of general organic chemistry. This reagent advances the highly reactive N-C amide bond in metal-free as well as transition metal catalyzed cross-coupling reactions yielding various carbonyl derivatives.

Distorted ring-amide can be represented generally by the correlation between the cleavage of lactam rings and the ring size. In Figure 10 and the corresponding Table 1 we summarize the possible alcoholysis of four to seven-membered lactams $(n=1-4)$ to open chain amino ester in the light of the calculated carbonylicity values. It is important to clarify, that the CA\% values are corrected with ring strain as described. The smallest ring-sized lactam (17a; $n=1$ in Figure 10) has relatively low carbonylicity value (40.5\%), which may be due to the insignificant conjugation and not only to the ring strain (Table 1). Thus, 17a can transform to the corresponding open-chain amino ester 18a, already having a normal value (ca. 56\%; Figure 10, Method-A). Generally, five- and six-membered rings $(\mathbf{1 7 b}, \mathrm{n}=2$ and $\mathbf{1 7} \mathrm{c}, \mathrm{n}=3)$ are the most stable among the small ring lactams, so one-step alcoholysis reactions are not allowed. More precisely, for five-member ring lactam $\mathbf{1 7 b}$ this one-step process toward $\mathbf{1 8 b}$ is forbidden due to the negative change of the carbonylicity value $(\Delta \mathrm{CA}=-3 \%)$, while in the case of six-member lactam the ring opening process $(\mathbf{1 7 c} \rightarrow \mathbf{1 8 c})$ exhibits an almost neutral change $(\triangle \mathrm{CA}=+1 \%)$. In these cases, a more complicated multi-step processes $(\mathbf{1 7} \rightarrow \mathbf{1 9} \rightarrow \mathbf{2 0} \rightarrow \mathbf{1 8}$; Method-B) should be used to cleave the lactam ring effectively. In this longer process, the hydrolysis with $\mathrm{NaOH}$ is allowed due to the increasing $\mathrm{CA} \%(\mathbf{1 9 b}, \mathbf{c})$. The acid chloride formation $(\mathbf{2 0 b}, \mathbf{c})$ activates their functionalities, which easily transform to the desired ester $\mathbf{1 8 b}, \mathbf{c}$. Finally, the seven membered lactam $(17 \mathrm{~d} ; \mathrm{n}=4)$ has a slightly lower carbonylicity value $(53 \%)$, which allows a moderate potency to transform it to $\mathbf{1 8 b}$ in alcohol in one step, with slightly increasing $\Delta C A$. It should be mentioned that the longer procedure $\mathbf{1 7} \rightarrow \mathbf{1 9} \rightarrow \mathbf{2 0} \rightarrow \mathbf{1 8}$ is available for all ring sizes.

Table 1. The calculated carbonylicity values (CA\%) of compounds $\mathbf{1 7 a}-\mathbf{d}$ and $\mathbf{1 8 a}-\mathbf{b}$ and the carbonylicity changes $(\triangle \mathrm{CA})$ for ring-opening alcoholysis depending on the ring size.

\begin{tabular}{ccccc}
\hline State & $\mathbf{n = 1 ( a )}$ & $\mathbf{n = 2 ( a )}$ & $\mathbf{n = 3 ( a )}$ & $\mathbf{n = 4 ( a )}$ \\
\hline Start (CA $\%) 17$ & $46.5 \%$ & $60.3 \%$ & $55.2 \%$ & $53.4 \%$ \\
Product (CA \%) 18 & $56.2 \%$ & $56.1 \%$ & $56.1 \%$ & $56.2 \%$ \\
$\Delta$ CA & $+10.7 \%$ & $-4.2 \%$ & $+0.9 \%$ & $+2.8 \%$ \\
Method & A or B & only B & A $^{1}$ or B & A or B \\
\hline \multicolumn{5}{c}{ Extremely slow reaction. }
\end{tabular}




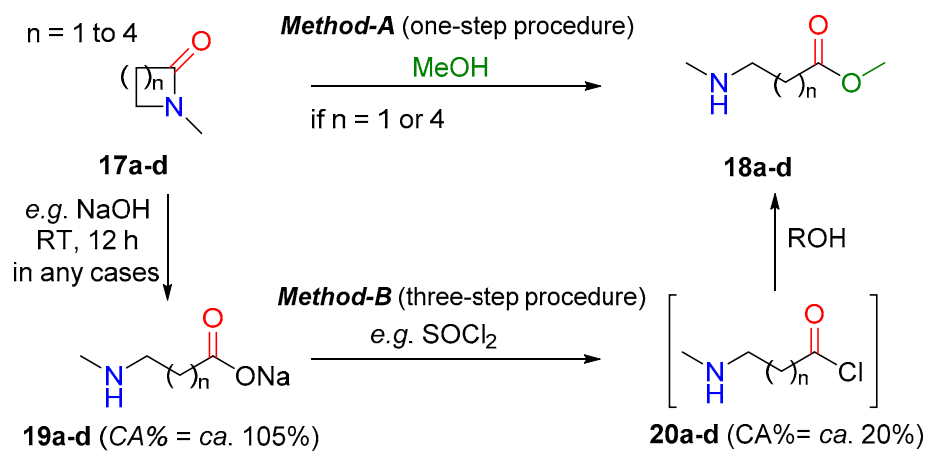

Figure 10. One step (Method-A; top) and multi-step (Method-B, bottom) procedures to transform cyclic amide (lactam) with various ring sizes to amino ester (for the corresponding carbonylicity values computed at B3LYP/6-31G(d,p) level of theory; see Table 1). The carbonylicity values for 19 and 20 are average values.

Some examples of sterically hindered amides were reported [70-72] to exhibit moderately low amidicity and carbonylicity values. One representative example is $\mathbf{2 1}$, where the amide functionality is sterically hindered and, hence, distorted. Here, somewhat decreased carbonylicity makes the reaction possible with alcohol (for example $\mathrm{MeOH}$ ) to yield an ester (22), as published earlier (Figure 11, top) [73]. Another example shows that a twisted amide (e.g., 23), having an extremely low amidicity value, readily cleaves its $\mathrm{CO}-\mathrm{N}$ bond by $\mathrm{MeOH}$, resulting an open-chain amino-ester (24), as shown in Figure 11 (bottom). In both cases, the thermodynamic driving force can be easily explained by the positive change in carbonylicity [74,75]. The combination of the twisted amide and acyl-anilide concepts are also exemplified, where these amides furnish effective alcoholysis analogously to the previous cases $[73,76]$.

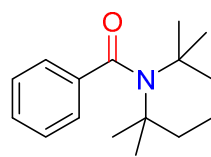

21

$\mathrm{AM} \%=88.2 \%$

$\mathrm{CA} \%=51.1 \%$

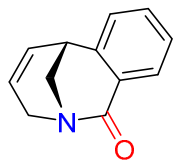

23

$\mathrm{AM} \%=-9.0 \%$

$\mathrm{CA} \%=13.7 \%$

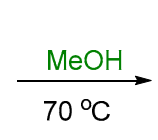

(1)

22

$\mathrm{CA} \%=57.2 \% \quad \Delta \mathrm{CA}=+6.1 \%$

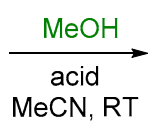

$\mathrm{MeCN}, \mathrm{RT}$<smiles>COC(=O)c1ccccc1C1C=CCNC1</smiles>

24

$\mathrm{CA} \%=56.6 \% \quad \Delta \mathrm{CA}=+42.9 \%$

Figure 11. Relevant examples for acyl transfer reactions in the cases of distorted (21) and twisted amides (23) resulting esters (22 and 24), explained by the change in carbonylicity (CA\%) with the corresponding carbonylicity and amidicity values computed at B3LYP/6-31G $(d, p)$ level of theory.

\subsubsection{Transamidation Reaction via Activated Amides (case III)}

Non-strained secondary amides (e.g., $N$-metylacetamide; 25) exhibit approximately $100 \%$ amidicity, so are typically not able to take part in transamidation reactions. For instance, the reaction between 25 and dimethylamine, yielding theoretically dimethyl acetamide (26), is not beneficial, due to the slightly smaller amidicity [40]. From the perspective of practicing chemists, there was a synthetic demand to activate and use these amides as reagents. To activate these resistant secondary amides, their high amidicities should be decreased by an activating group. Numerous methods were developed 
in recent decades and presented in the literature, summarized in Figure 12. All these solutions involve a preliminary activation step.

The introduction of $N$-nitroso (27) [77,78], $N$-nitro (28) [79], $N$-(tosyl) (29) [80], $N$ (trifluoromethanesulfonyl) (30) [80], or $N$-acyl (31) [81-83] amides are the most relevant examples. The following step describes how these activated amides (27-31) could react with, e.g., dimethylamine, to yield the desired and exemplified amide product 26. The byproducts of these reactions are typically good leaving groups. The most significant amidicity decrease can be measured for $\mathbf{2 8}$ and 30, producing the most reactive acylating agents $[79,80]$. The $N$-BOC-N-methyl-acetamide 31 was prepared in a previous step from 25 by (BOC) ${ }_{2} \mathrm{O}$ reagent [82,83], a process known as $N$-Boc activation. Other, bisacyl and triacyl substituted amides (such as succinimide [84] and phthalimide derivatives [85]) may also behave as good transamidating agents in the presence of an amine. In all cases, the listed $\Delta \mathrm{AM}$ values were large enough to provide enough driving force to convert to the desired product 26 [40].
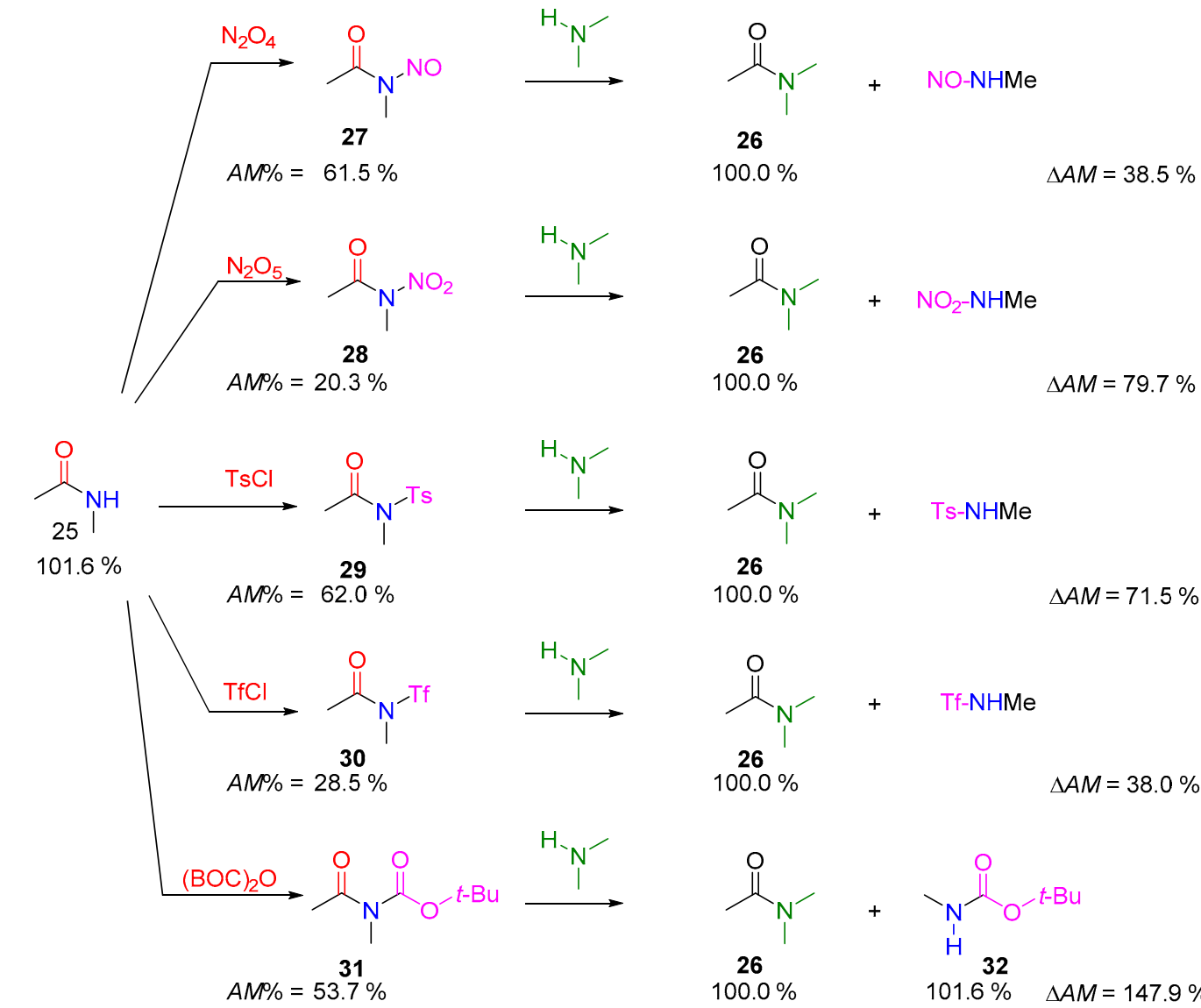

$+\quad$ Tf-NHMe
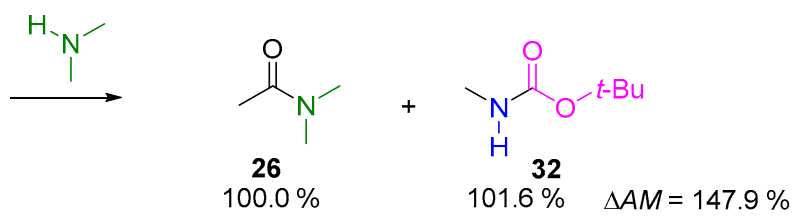

Figure 12. Some representative examples of amide activations (case III), using various reagents with the corresponding amidicity values computed at B3LYP/6-31G $(\mathrm{d}, \mathrm{p})$ level of theory. Ts = $p$-toluenesulfonyl; $\mathrm{Tf}=\mathrm{CF}_{3} \mathrm{SO}_{2}-; \mathrm{BOC}=t-\mathrm{BuO}-\mathrm{CO}-$.

Finally, a good example can be found for the transition metal catalyzed transamidation, where $\mathrm{N}$-alkyl-benzamide (e.g., 33) was transformed to dialkyl derivatives (e.g., 34a). The authors previously reported that $\mathbf{3 3}$ could not be transformed to $\mathbf{3 4 a}$ directly, even in the presence of an active transition metal catalyst (Ni/SIPr), without providing any theoretical interpretation. However, the amidicity concept is able to highlight the thermodynamic background of the process failure, due to the unfavorable amidicity change $(\triangle A M=-16.4 \%$ in Figure 13). Nevertheless, with the activation of the amide by BOC group (35), the progress occurs smoothly to product 34a, in the presence of $\mathrm{Ni} / \mathrm{SIPr}$ catalyst. It seems reasonable to conclude that when the transamidation reaction exhibits positive amidicity change (as in $35 \rightarrow 34$ ), the transition metal catalyst or any other catalyst may help. 
However, when the reaction is substantially endothermic (as in $\mathbf{3 3} \rightarrow \mathbf{3 4 a}$ ), the reaction will not take place even if catalyst is used.

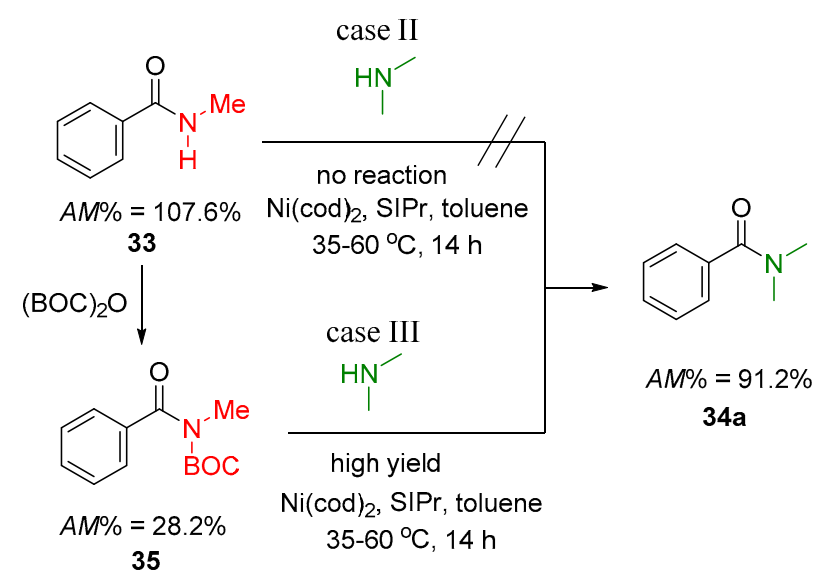

Figure 13. Exemplified transamidation reaction of 33 (case III) with $(33 \rightarrow 35)$ and without amide activation. The corresponding amidicity values were computed at B3LYP/6-31G(d,p) level of theory. $\mathrm{BOC}=t$-BuO-CO-; $\mathrm{cod}=1,5$-cyclooctadiene; SIPr = 1,3-bis(2,6-diisopropylphenyl)imidazole-2-ylide.

Analogues reactions can be found in the literature, where variously substituted amide compounds are used as a reagent to convert them to ester derivatives with the corresponding alcohol. Some examples are summarized in Figure 14, where substituted benzamide derivatives (33-34a,b) could be converted to 22 . Clearly, these reactions can occur, if the carbonylicity difference is favorable. In the case of the transformation of $33(\mathrm{R}=\mathrm{H})$ to 22 , the reaction is forbidden due to the negative change in carbonylicity, with or without catalyst (Figure 14). The transformation of $\mathbf{3 4 a}$ to 22 is theoretically possible, but the reaction condition applied in the publication was not harsh enough to be effective (Figure 14, case II). In the case of Ph substituents (35), however, maintaining low amidicity value is sufficient to enable the acyl transfer in the presence of Ni/SIPr catalyst [50]. Finally, 33 can transform to 22 effectively by the activation method with (BOC) $)_{2} \mathrm{O}$ reagent (Figure 14, case III). The prepared active intermediate $\mathbf{3 4 b}$, having a low amidicity value, finally can be transformed to the ester product, in the presence of $\mathrm{Ni} / \mathrm{SIPr}$ catalyst.

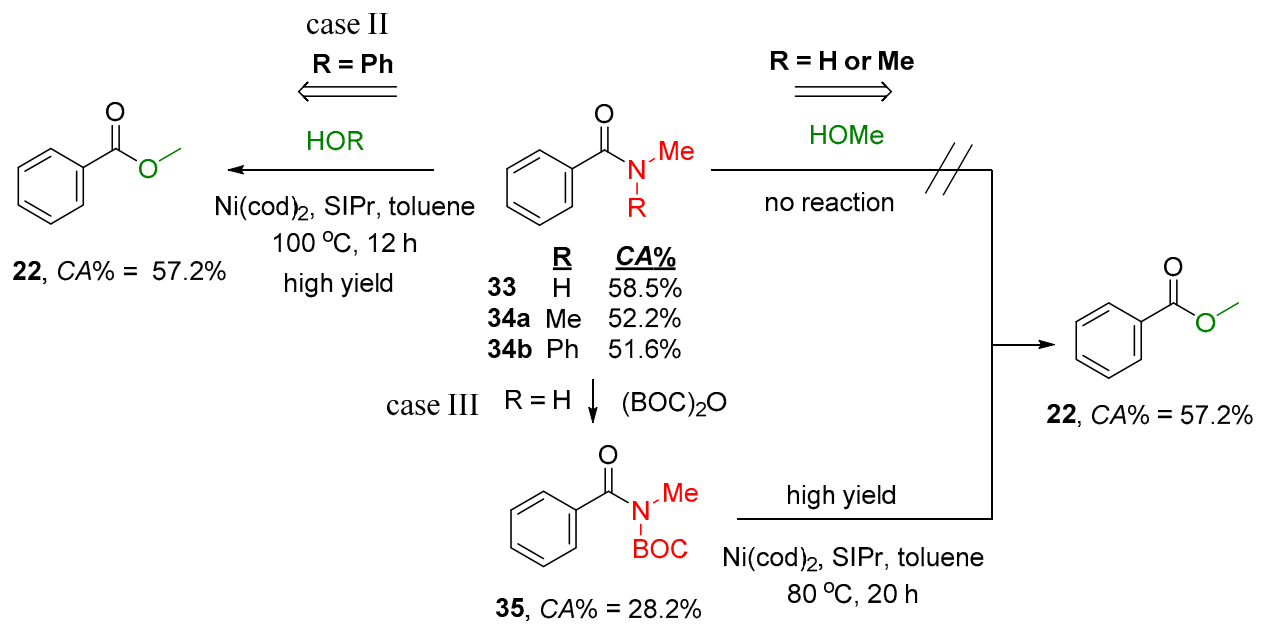

Figure 14. Exemplified acyl transfer reaction (case II and case III) with and without amide activation in the presence of catalyst. The corresponding carbonylicity values were computed at B3LYP/6-31G(d,p) level of theory. BOC = t-BuO-CO-; $\operatorname{cod}=1,5$-cyclooctadiene; SIPr = 1,3-bis(2,6diisopropylphenyl)imidazole-2-ylide. 
From these examples it becomes clear that there is no fundamental difference between transamidation reaction and other transacylation, because in both cases there is an acyl migration. However, for historical reasons, the transamidation and acyl transfer processes are still distinguished in the literature. Needless to say, all of these conclusions are true when the heteroatom is sulfur.

The reverse pathway with different substituent patterns, the transacylation from ester to amide, was also described in the literature in the presence of Ni/SIPr catalyst [86-88].

\subsubsection{Activated Transamidation Reaction via Product Stabilization [case IV]}

Because of its high amidicity value, $N, N$-dimethyl formamide (DMF; Figure 15) can be considered an unreactive amide. In contrast to this, deprotonated amides, such as 36, possess even higher amidicity values $(>150 \%)$ than tertiary amides. In strongly basic conditions, deprotonated amides (36) should, therefore, be more favorable than non-deprotonable DMF. A good example is found in the literature, where aniline derivatives $37 \mathbf{a}-\mathrm{c}$ can be deprotonated by $\mathrm{NaH}$ or $\mathrm{NaOMe}$, generating their corresponding anion form of 38a-c. The product amide anions $36 \mathbf{a}-\mathbf{c}$ were formed at elevated temperature (Figure 15) [36,89-91]. During the workup process, an aqueous acid was used to acidify and precipitate the neutral product $39 \mathbf{a}-\mathbf{c}$ in an irreversible way. The procedure as a whole is a thermodynamically forbidden transformation ( $38+\mathrm{DMF} \rightarrow 39)$, due to the lower amidicity of the product 39a-c. Nevertheless, only the reversible subprocess of $\mathbf{3 8}+\mathrm{DMF} \rightarrow \mathbf{3 6}$ (in green box, Figure 15) is favorable. Overall, the driving force of this subprocess is controlled by the high $\triangle \mathrm{AM}$, so this formylation reaction is rapid, making this reaction practical [40].

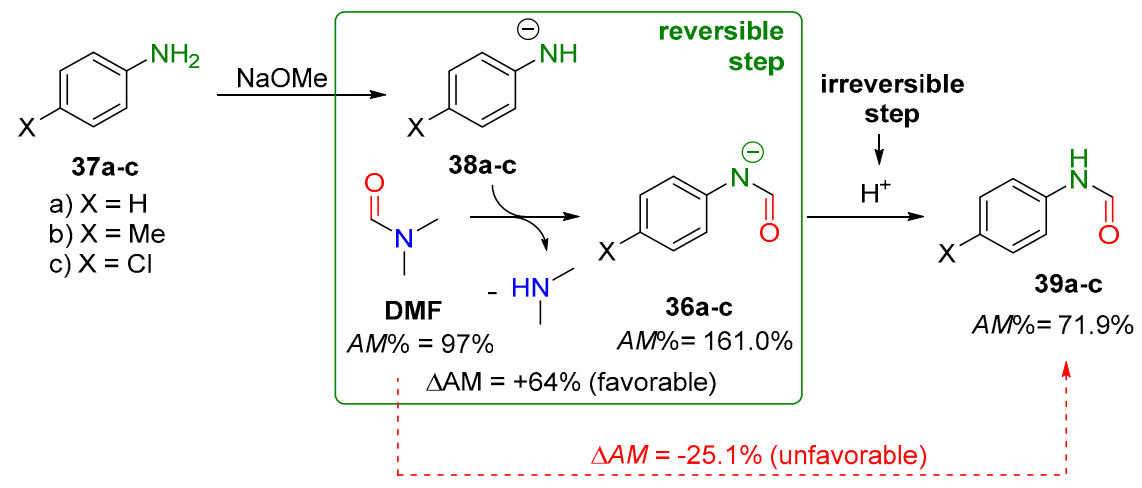

Figure 15. An example for case IV transamidation reaction with the corresponding amidicity values computed at B3LYP/6-31G(d,p) level of theory. The green box illustrates the thermodynamically favorable subprocess, while the red arrow shows the overall unfavorable reaction.

The use of the amidicity change ( $\triangle \mathrm{AM}$ ) leads to a quasi-thermodynamic selection rule, allowing the reactions to be categorized as being either thermodynamically favorable or unfavorable. This simple rule of amidicity-change may be used to predict the selectivity of a reaction, where two competing functional groups are involved. Such an example is presented, where two types of amino groups are attached in one molecule (40). As one may predict by the amidicity change, only the alkyl amine group will react with formamide, yielding 41 exclusively with high yields in one step (Figure 16). The other isomer amide $\mathbf{4 2}$ and the diacylated $\mathbf{4 3}$, including anilid type amide, could not be detected in the reaction mixture, as the amidicity change simply predicted [40]. 


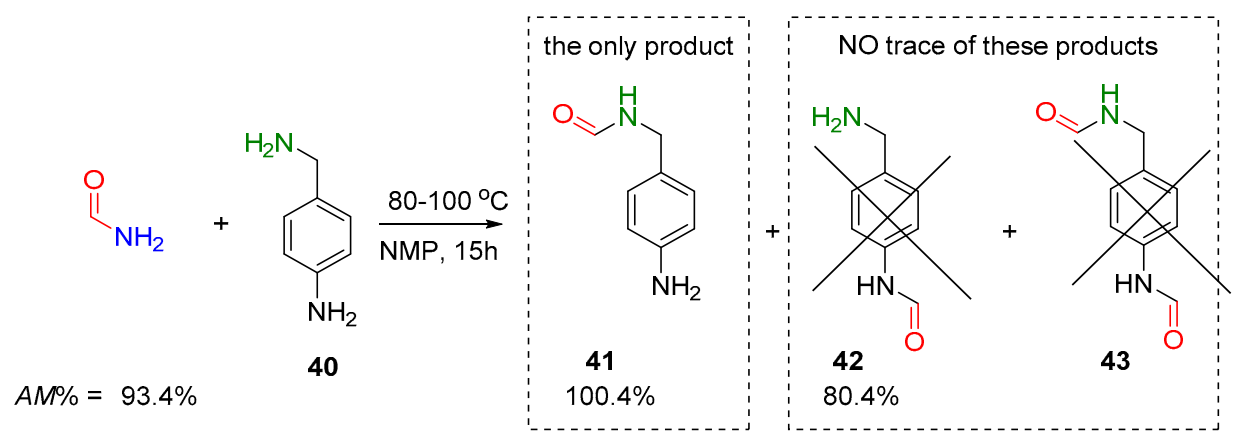

Figure 16. Selectivity of transamidation reaction of $N, N$-dimethylformamide (DMF) and compound 40, having two types of amino groups. The three possible products $\mathbf{4 1 - 4 3}$ are shown. The corresponding amidicity values were computed at B3LYP/6-31G(d,p) level of theory.

\subsection{Amide Reduction via Amide Activation}

An unprecedented number of examples can be found in the literature to reduce amides to substituted amines, using numerous reduction agents (most generally metal hydrides). The situation is illustrated by a few selected citations $[31,69,92-97]$. Strong reduction agents are a common feature of these methods, since generally amides are very resistant against reduction. Consequently, these methods are typically not applicable to carry out selective reactions. This extreme resistance can be explained by the strong conjugative interaction within the structure of amide, exhibited by their high amidicity values. Among the reduction agent $\left(\mathrm{LiAlH}_{4}\right.$ or $\left.\mathrm{BH}_{3}\right)$, the complex and highly active metal hydrides may have the most significant synthetic importance to obtain various amines.

However, selective examples can be found in the literature in which one of the amide groups was reduced selectively in one molecule, while keeping the other amide or other sensitive groups of the molecule untouched [98-101]. This was achieved by the activation of the selected amide group by an appropriate $\mathrm{N}$-substituting activating group. The following example illustrates this methodology in Figure 17, among other examples. The case of the exemplified diketopiperazine derivative 44 [101] includes two unequal but very similar amides, $A$ and $B$, from the aspect of amidicity. If one tries to reduce this compound 44 by $\mathrm{LiAlH}_{4}$, both the amides $\mathrm{A}$ and $\mathrm{B}$ will be reduced to piperzine derivative 45. From this reaction it would become clear for a practicing chemist, that no possibility exists of finding a selective reducing agent to obtain piperazidone derivative 46. In the case of adding only one equivalent of reductive agent, a complex mixture of partially reduced forms can be observed.

However, analogously to case III reactions in the previous section, the secondary amide-A was acylated by $\mathrm{BOC}_{2} \mathrm{O}$ reagent, which resulted in a triacylated intermediate 47 . In this structure, the amidicity of the acylated amide $\mathrm{A}$ is lowered to $34.6 \%$, while that of amide $\mathrm{B}$ increased slightly. The carbonyl of the BOC group (amide-C) is as high as $109.1 \%$, which exhibits large resistance to reduction. The lowered amidicity of the amide-A provides not only higher reactivity with the metal hydride, but allows the application of significantly weaker reducing agent, such as $\mathrm{NaBH}_{4}$. This reagent is soft enough to avoid the reduction of amide-B and $C$. In the first reduction step, amide-A is reduced only to hydroxy amine intermediate 48 , protected by the BOC group, but with increased amidicity for amide-C. This intermediate 48 was transformed finally to the desired product 46 by a consecutive deprotection and reducing steps. This compound later proved to be an excellent building block in drug research. This method is not limited only to six-member diketopiperazines, but it can also be generalized for even open chain systems [101]. 


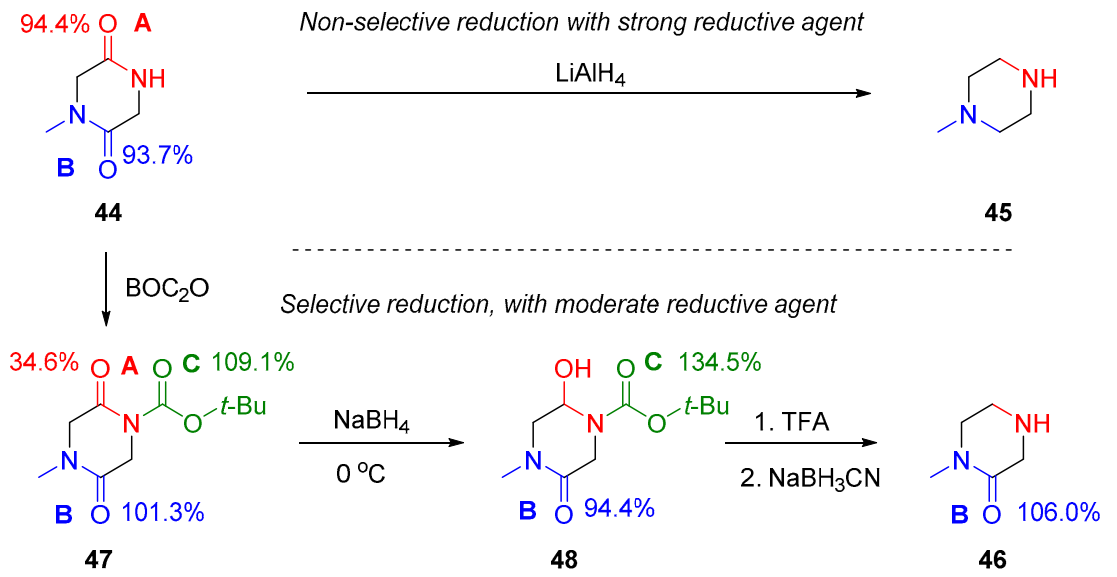

Figure 17. The non-selective and selective reduction of the amide bonds in a diketopiperazine derivative 44, including amide- $A$ and $B$, to yield 45 and $\mathbf{4 6}$. The corresponding amidicity values were computed at B3LYP/6-31G(d,p) level of theory.

\subsection{Amide Reaction in the Biochemistry}

Natural products are very precisely assembled from selected molecular components in unique arrangements. They typically exhibit very effective and targeted mechanisms of actions in numerous biological processes. There is an observably large difference in complexity, activity and efficiency of human-designed compounds [102] and nature's biomolecules, such as dinucleotide coenzymes (NAD and FAD) [103], calicheamicin- $\gamma 1$ [102,104,105], duocarmycin [106-108], syringolin A [18], aflatoxin B [18], and penicillin [109]. Biochemical processes also take advantage of the selectivity of acyl transfer reaction and amide activation, so three representative examples are presented in this section.

\subsubsection{Cross-Linking in the Blood Clotting Process}

The first example is taken from the multistep process of blood clotting [110-112]. In this case, in the final, thirteenth step (Figure 18) of the entire complex process, the two final protein intermediates 49 and 50 are linked to each other via a new side-chain amide bond [112].

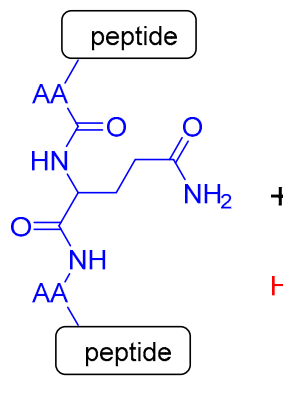

49

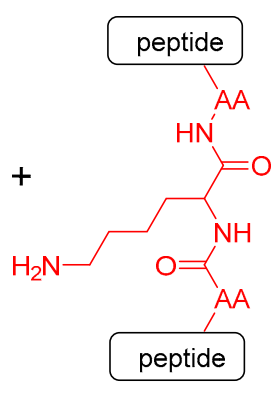

50

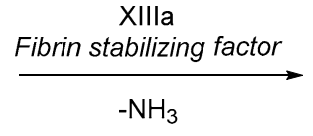

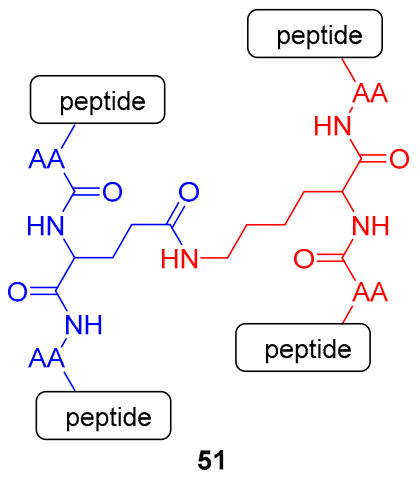

$A M \%=101.0 \%$

Figure 18. The final step of the blood clotting process from the aspect of amidicity change, catalyzed by the transamidinaze enzyme. The corresponding amidicity values were computed at B3LYP/6-31G(d,p) level of theory.

This creates a molecular polymeric net (51), which forms a barrier against bleeding. Analyzing the process from the aspect of amidicity values (Figure 18), this transamidation reaction is spontaneous. The process takes part between a glutamine side chain amide (blue) and a lysin side chain amine (red). 
The amidicity change is predicted to be slightly positive $(\triangle \mathrm{AM})$, because the initial $96.0 \%$ amidicity of the glutamine side chain amide is increased to $101 \%$ as the new amide is formed, not requiring additional activation. This small change in amidicity provides a driving force for this bioreaction, but it is not enough to exhibit the measurable high reaction rate at body temperature. Consequently this process is catalyzed by an enzyme fibrin stabilizing factor or transglutaminase [112,113]. Moreover, the releasing ammonia also makes the process irreversible.

\subsubsection{Intein-Mediated Protein Splicing}

Intein-mediated protein splicing is a biologically important process (Figure 19) [114-117], where a small but defined part of the protein 52, intein (53), is cut out specifically from the middle of a protein. Meanwhile, the two remaining parts, called exteins, are linked to each other, forming a new protein 54 via a new peptide bond. Protein splicing is so rapid that the precursor protein is rarely observed in native systems. It was shown that the process is auto-catalytic and folding-dependent [118-120]. The N-extein residues play unique and important roles in protein splicing [120]. The intein peptide sequence is supposed to contain no sufficient information originating from an external source [114-117].

From the chemical aspect, here two amides are involved in transamidation process rather than an amide and an amine shown previously [33]. The intein and the C-terminal extein residue contain sufficient information for splicing in proteins, which involves four basic chemical steps. In the first step of the mechanism [114-117], the serine or cysteine residue, at the N-terminal border of the intein, attacks the neighboring peptide bond forming an intermediate 55 , which in a subsequent step rearranges to 56 and $\mathbf{5 7}$. In the final step, the intein leaves the native sequence resulting in the edited protein 54. Taking into account only the starting and ending state, the overall process exhibits a large negative $\triangle \mathrm{AM}$ value $(-45 \%)$, which may suppose an endothermic reaction. One may argue that the exothermic refolding of the instantly cut intein sequence provides additional driving force, covering the energy demand of the overall amidicically unfavorable process. Moreover, the N-extein-intein amide linkage is a typically distorted amide (blue in Figure 19.) due to the folding, resulting in lower amidicity, which could initiate the acyl migration (blue arrow).

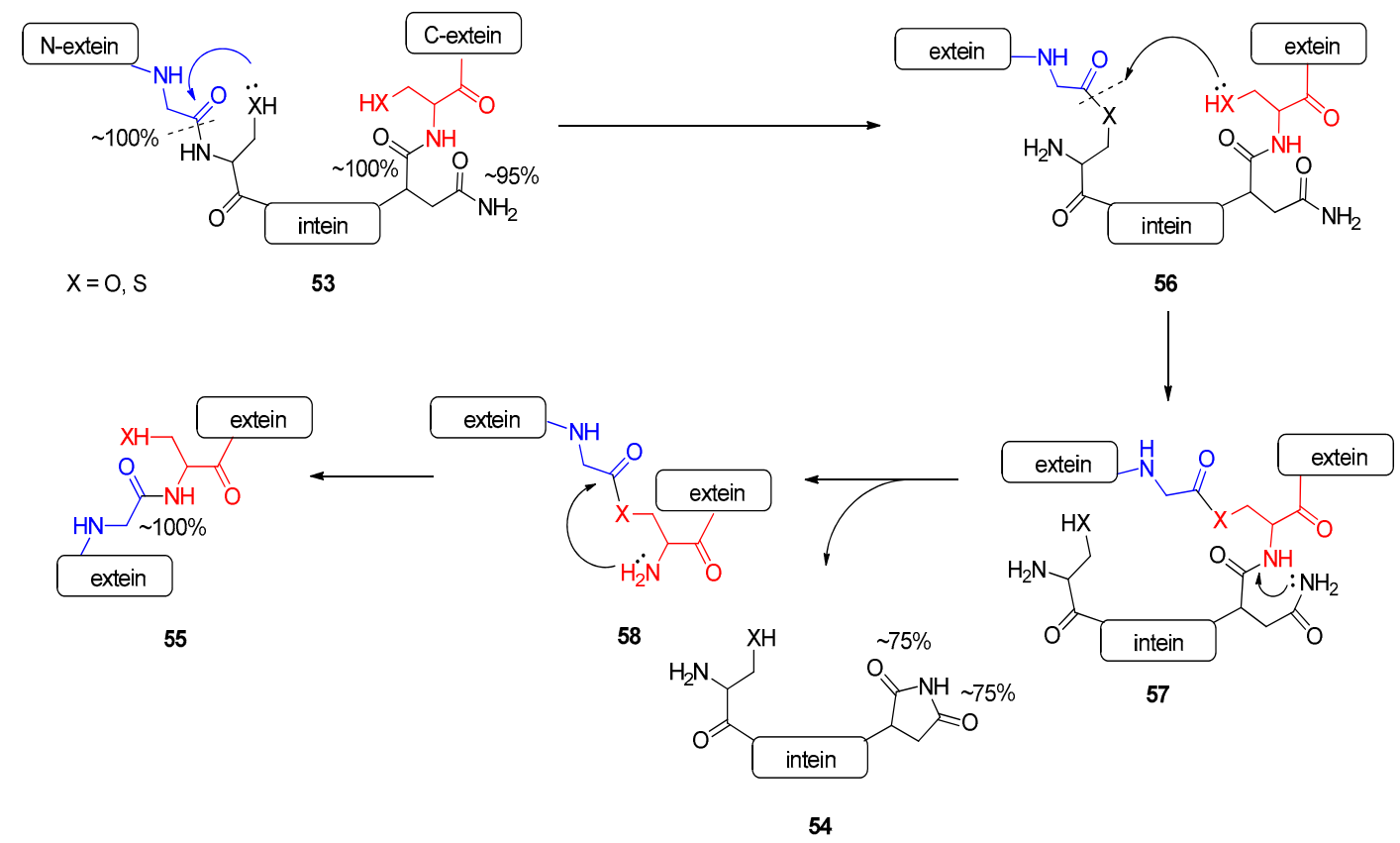

Figure 19. The mechanism of action of protein splicing as a special type of transamidation reaction. 


\subsubsection{Penicillin}

One of the most important small biogen amides is penicillin (58), produced by the Penicillium genus, which is considered to be one of the great discoveries of the 20th century [121,122]. This antibiotic inhibits penicillin binding proteins, such as transpeptidase, by blocking their serine residue via acylation in gram-positive bacteria. In this way, bacterial cell wall synthesis stops, leading to deadly susceptibility to osmotic effects and cell bursting. This bacterial enzyme plays a crucial role in transferring the D-Ala-D-Ala dipeptide into the bacterial cell wall synthesis as illustrated by Figure 20. The perennial war between bacteria and fungus led to the evolution of $\beta$-lactam related antibiotics, and resulted in many variants, of which cephalosporine [123] and thienamycin [124,125] are just two examples.

During the last century, resistant bacteria strains have developed some defending mechanisms against intensively and overused $\beta$-lactam antibiotics. Consequently, antibiotic research is once again at the forefront of drug research. The $\beta$-lactamase enzyme is synthesized by resistant bacteria for deactivation of penicillin-type compounds in order to avoid their lethal effects [122,126-129]. Regardless, continued characterization of the $\beta$-lactam structure and mechanism aids in the understanding and design of novel antibiotics with desired effects and great precision [126].
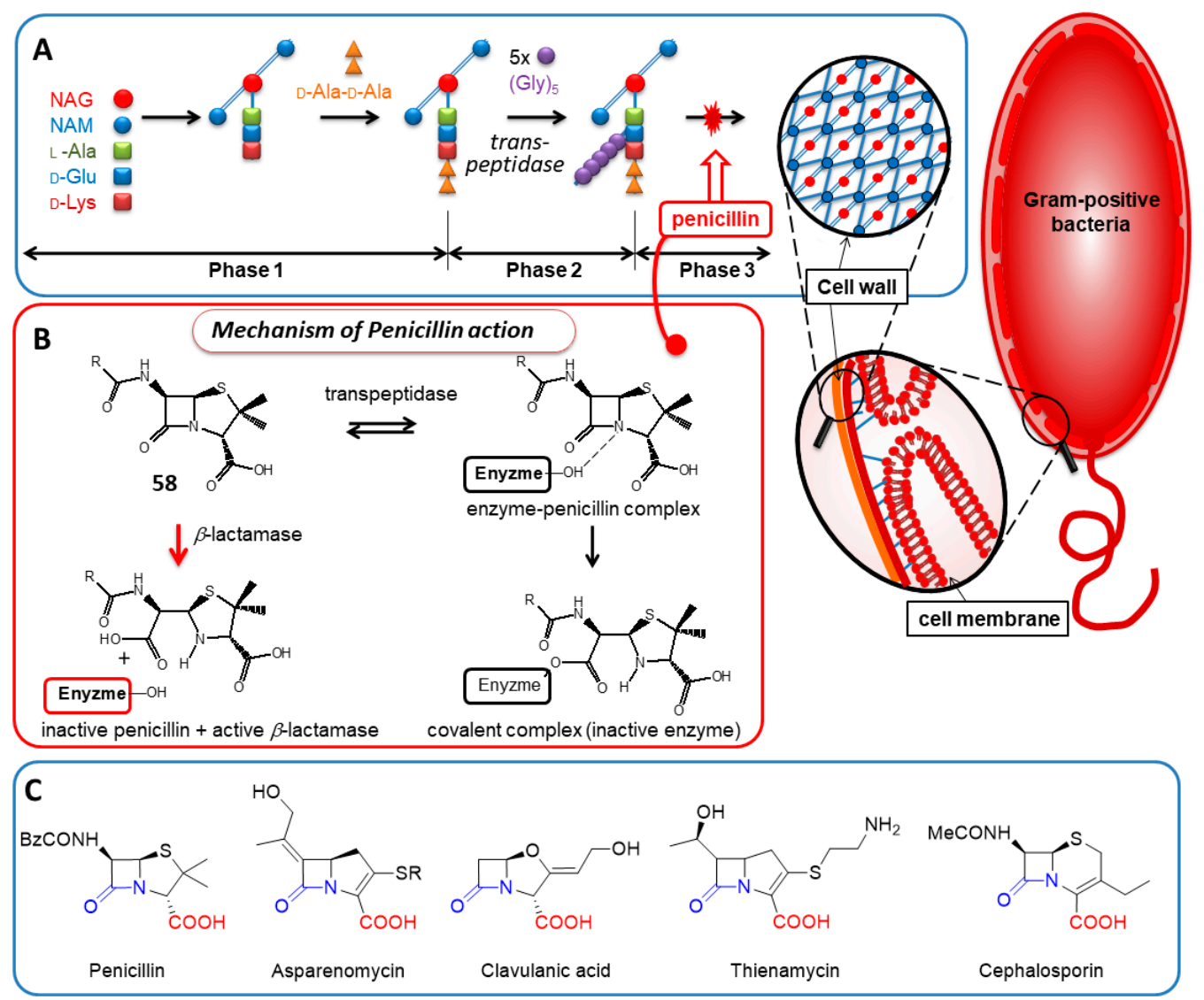

Figure 20. (A) The schematic mechanism of biological action of the penicillin antibiotic in the course of cell wall synthesis. (B) Penicillin inhibits transpeptidase enzyme by bonding covalently to the serine side-chain producing non-hydrolysable enzyme-substrate complex, blocking irreversibly the enzyme activity. (C) Some representative examples of $\beta$-lactam antibiotics. Their common feature is the strained $\beta$-lactam ring neighbouring a carboxylic functionate, which are both essential for the antibiotic activity. NAG $=N$-acetylglucoseamine; NAM $=N$-acetylmuramic acid.

Since the discovery of penicillin's chemical structure [18,129], the way this molecule avoids the aqueous hydrolytic effects in body fluid, while immediately awakening its hidden ability to acylate 
the transpeptidase's serine side-chain oxygen, has remained a mystery $[130,131]$. Recently, bacterial resistance has been investigated intensively, wherein penicillin hydrolysis was studied [131-135], and on the bases of this mechanism its activity was understood [132-134]. The "strange" fused $\beta$-lactam-type structure [132] was dedicated to explain its strength as an acylating agent completely, approximated earlier to that of acyl chlorides [133,134]. In organisms, however, such a strong acylating agent should decompose quickly before reaching its destination, e.g., the transpeptidase enzyme of the bacteria.

Previously, it was shown that the unexpected stability of penicillin can be attributed to its deprotonated form (59 in Figure 21), which is the dominant component of the neutral aqueous environment [60]. According to the new, higher level quantum chemical calculations at MP2(full)/DGDZVP, the amidicity value [40] of the anion form was found to be higher (AM\% $=71.7 \%$ ) than the neutral form (58), referring to the more stable amide bond in the anionic form. However, when the penicillin reached its target enzyme, the transpeptidase, it gets protonated (59 in Figure 21) by the enzyme. The forming neutral form of penicillin (58) immediately lowers its amidicity to $22.1 \%$, so it has been triggered for the reaction. Finally, the $\mathrm{H}$ atom on the carboxylic acid group can also easily turn back to the pyramidaziled amid $\mathrm{N}$ atom, forming an $\mathrm{H}$-bond. This conformational change turns on the final, superactive form of the molecule (60 in Figure 21), reflected by the extremely low amidicity $(\mathrm{AM} \%=-8.7 \%)$. This form instantaneously makes a covalent enzyme-drug complex, and knocks out the enzymatic activity. This carboxylic function makes the molecule a well-designed acylating bacteria killer, because it also acts as a bait for the essential bacterial enzyme. In this way, penam scaffold antibiotics are practically self-activating selective hitmen against bacteria. In summary, penicillin provides an interesting example of a controlled protonation and conformation-dependent amide bond activation.

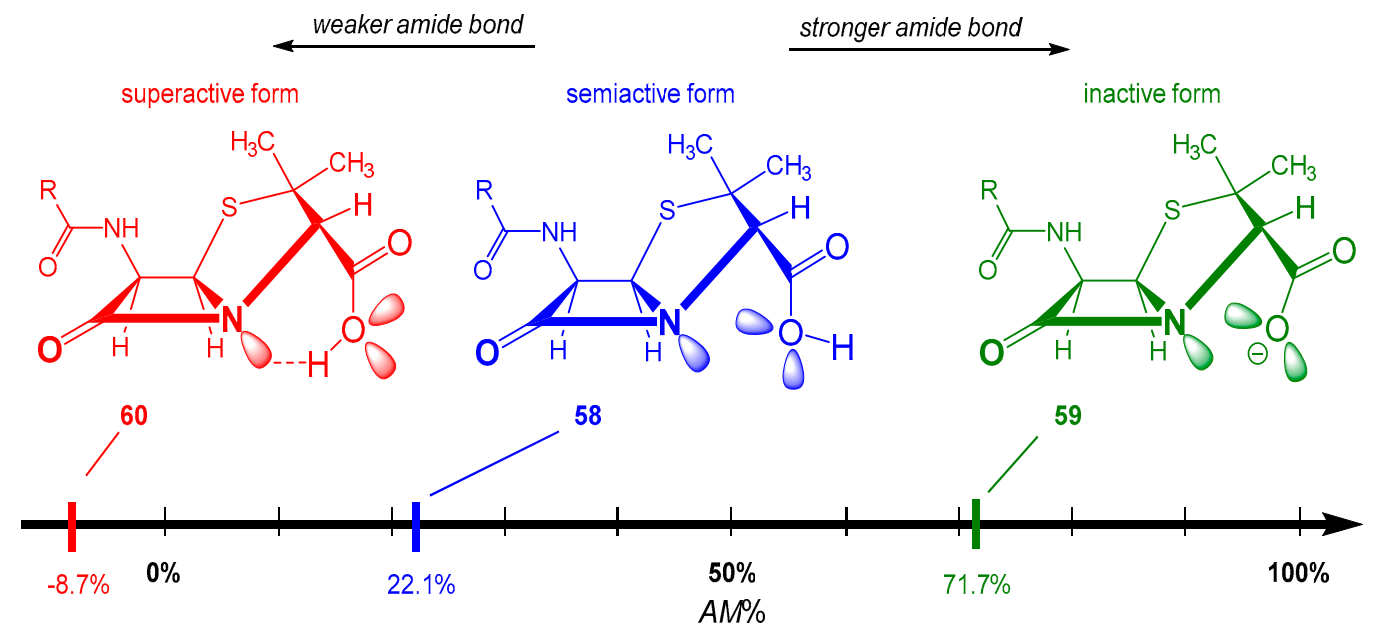

Figure 21. The amidicity scale [MP2(full)/DGDZVP], showing the reactivity of the carbonyl group for the three different forms of penicillin molecule $(58,59$ and 60$)$, depending on its protonation degree as well as its conformation. The electron repulsion between the $\mathrm{COO}-$ group and the $\mathrm{N}$ atom is illustrated by the lone pairs. This strengthening of the amide bond in 59 (larger amidicity) decreases reactivity with respect to 58 . In form 60 , the internal $\mathrm{H}$-bond withdraws density from the amide bond, weakening it (extremely low amidicity) leading to extremely high reactivity toward nucleophiles.

\subsection{Amide Activation in Excited State.}

The electronic excitation of the chromophore functionality is able to transfer the energy toward a neighboring amide bond, resulting in an amide activation and in an increased reactivity of the amide bond, which is utilized for various processes [33]. Photocleavage (also known as uncaging) is based on this phenomenon, providing a methodology to release selectively a bioactive compound from its covalently bonded cage-form in a localized volume. Otherwise, the cage scaffold should effectively 
block the activity of the bonded biomolecule, but undergoes efficient removal after excitation of the moiety, through the scissile bond. Until now, numerous cage molecules have been developed (Figure 22); however, nitro-indoline and coumarine scaffolds are the most popular of these, and are usually linked with glutamate as excitatory neurotransmitter [136,137].

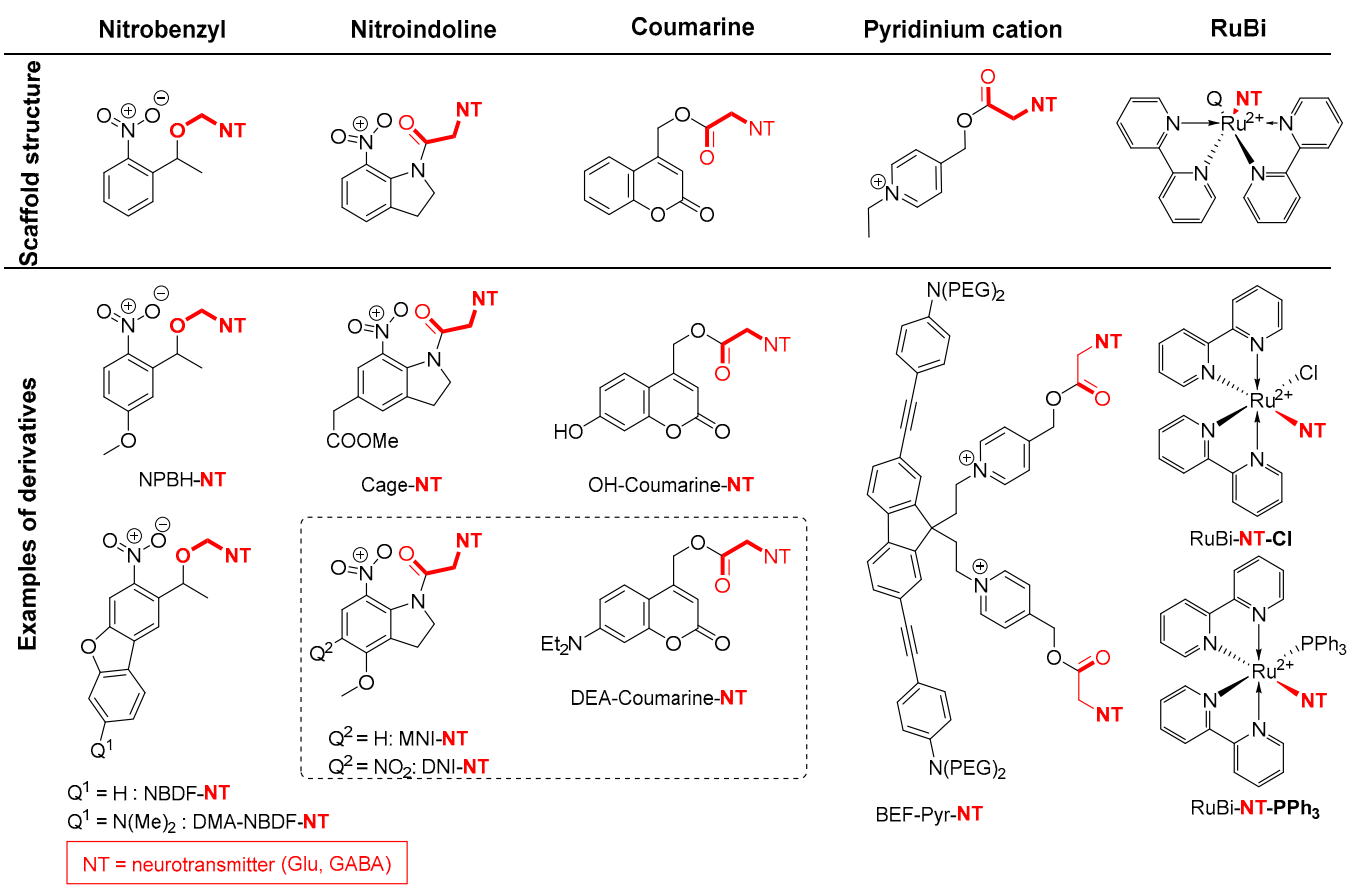

Figure 22. Collection of the most prominent cage-scaffolds (top) and some derivatives (bottom). NT $=$ neurotransmitter. Compounds in the box are the subject of discussion.

\subsubsection{Photochemical Release of Glutamate from MNI-Glu and DNI-Glu at Excited State}

The most popular cage compounds, 5-mono-nitro-indoline (MNI) and 5,7-dinitro-indoline (DNI), have proved their effectiveness during the last decade and have been widely applied in numerous neuroscientific papers. Due to the large number of scientific results, in this paragraph we focus only on DNI-Glu and MNI-Glu [138]. MNI-Glu and DNI-Glu fulfill the main requirements for an ideal cage compound, including an efficient uncaging process with relatively high chemical yield, rapid two-photon induced release (quantum yield 8.5\%) [139], low spontaneous hydrolysis rate, (Figure 23) and low biochemical side effects [140]. These properties were demonstrated to be useful in neurophysiological experiments.

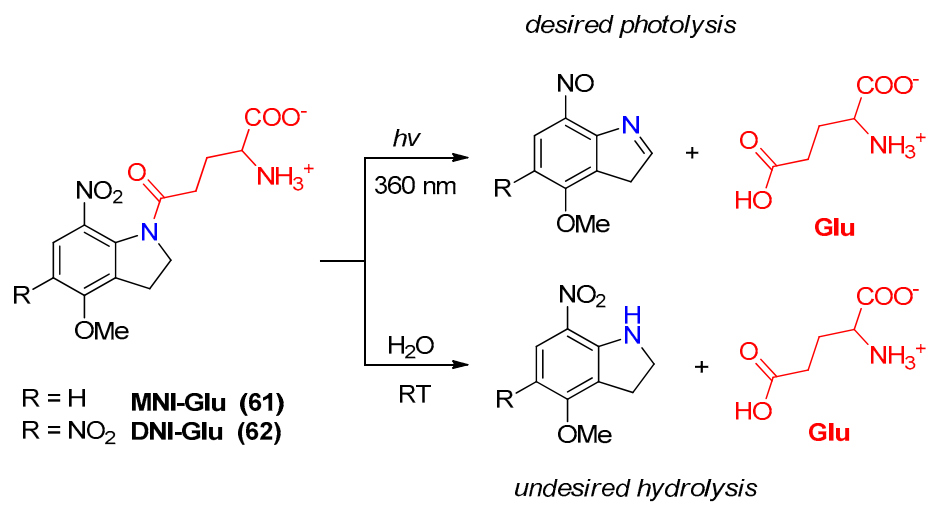

Figure 23. Chemical structures of MNI-Glu $(\mathrm{R}=\mathrm{H})$ and DNI-Glu $\left(\mathrm{R}=\mathrm{NO}_{2}\right)$ and their photochemical reactivity (top) and hydrolytic reactivity (bottom). 
The reaction mechanisms of the desired photochemical glutamate release of MNI-Glu (61) and DNI-Glu (62) were studied and compared on quantum chemical bases using GAUSSIAN 09 software [141] (Figures 24 and 25). Their reaction profile proved to be identical, but the energy values varied in a significant range (4-10 kJ/mol). Here, only the photochemical reaction of DNI-Glu (62) will be presented. The photocleavage of DNI-Glu (62) starts from the initial state A(S0) and follows the sequence of $\mathrm{A} \rightarrow \mathrm{B} \rightarrow \mathrm{C} \rightarrow \mathrm{D} \rightarrow \mathrm{E} \rightarrow \mathrm{F} \rightarrow \mathrm{G}$. The inadvertent ground state hydrolysis in aqueous media $(\mathrm{A} \rightarrow \mathrm{I})$ also plays an important role during the applications, but will not be discussed here.

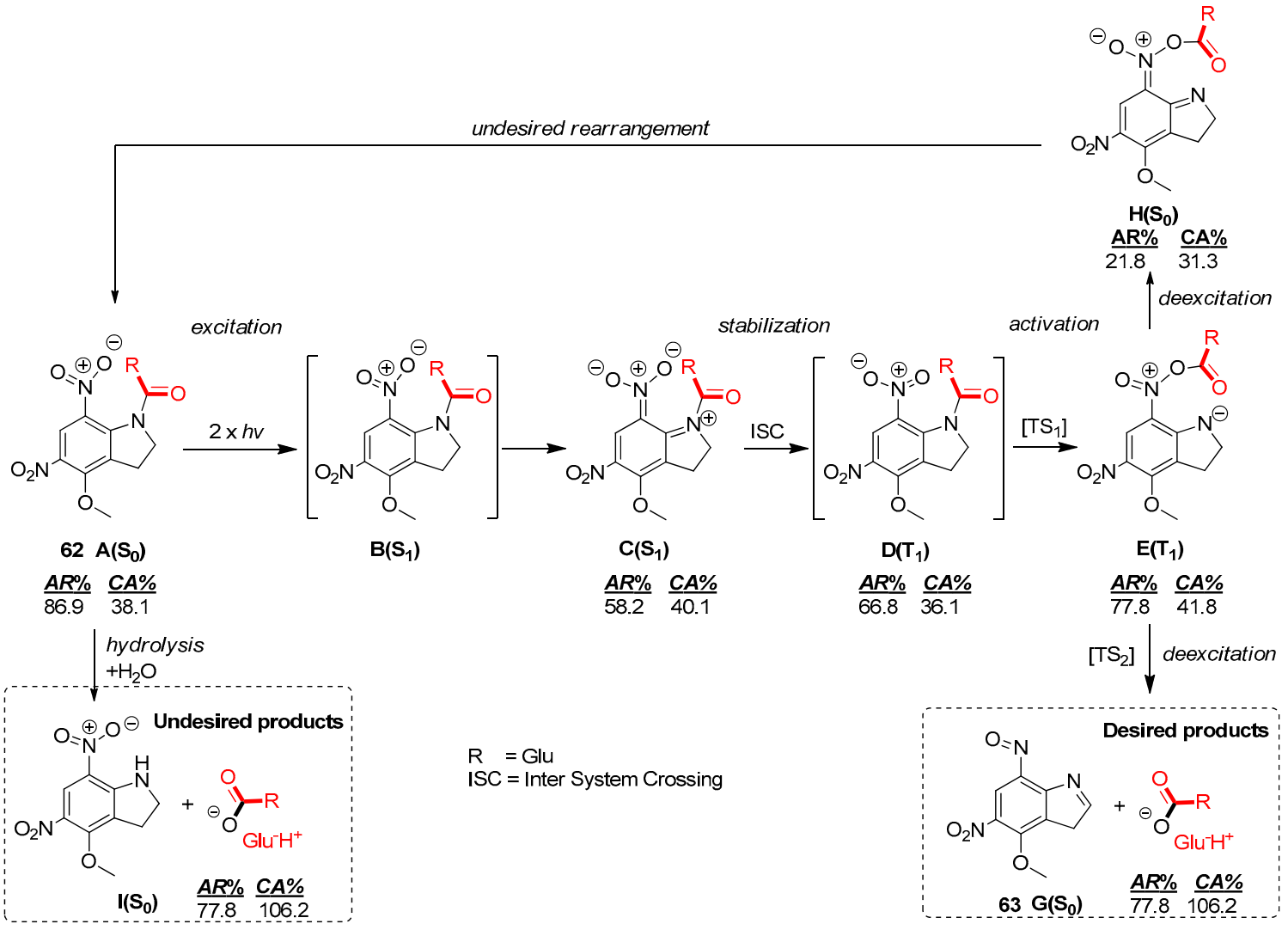

Figure 24. Quantum chemical modelling of the photochemical reactions as well as the simplified mechanisms of ground state hydrolysis for DNI-Glu (62). The aromaticity (AR\%) of the benzene ring and carbonylicity of the carbonyl functionality along the mechanism are computed at B3LYP/6-31G(d,p)//PCM(water) level of theory [37].

After the excitation of the aromatic antenna moiety of DNI-Glu [62; $\left.A\left(S_{0}\right) \rightarrow B\left(S_{1}\right)\right]$ the structure follows a vibrational relaxation $\left[\mathrm{B}\left(\mathrm{S}_{1}\right) \rightarrow \mathrm{C}\left(\mathrm{S}_{1}\right)\right]$. The high energy excited singlet state $\mathrm{C}\left(\mathrm{S}_{1}\right)$ tends to transform to a triplet state $\mathrm{D}\left(\mathrm{T}_{1}\right)$ via an intersystem crossing (ISC) process. The triplet state intermediate takes part in an acyl transfer reaction, where the acyl group migrates from the indoline $\mathrm{N}$ atom to one of the $\mathrm{O}$ atoms of the nitro group through a low energy barrier (TS1). This process finally results in an unusually stable triplet state $\left[\mathrm{E}\left(\mathrm{T}_{1}\right)\right]$. Here, the mechanism may proceed in two different directions. The desired product state, including the free glutamate [Product $1 ; \mathrm{G}\left(\mathrm{S}_{0}\right)$ ], is achieved by the $\mathrm{N}-\mathrm{O}$ bond cleavage at stage $\mathrm{E}\left(\mathrm{T}_{1}\right)$ through $\mathrm{TS} 2$, leading to a relatively high energy state $\mathrm{F}\left(\mathrm{T}_{1}\right)$. Finally, the deexcitation to ground state $\left[\mathrm{G}\left(\mathrm{S}_{0}\right)\right]$ results in the final products. However, due to the relative stability of the triplet state $\mathrm{E}\left(\mathrm{T}_{1}\right)$, it can undergo a deexcitation process to give a very reactive species $\mathrm{H}\left(\mathrm{S}_{0}\right)$, which can return to the starting state $\mathrm{A}\left(\mathrm{S}_{0}\right)$. 


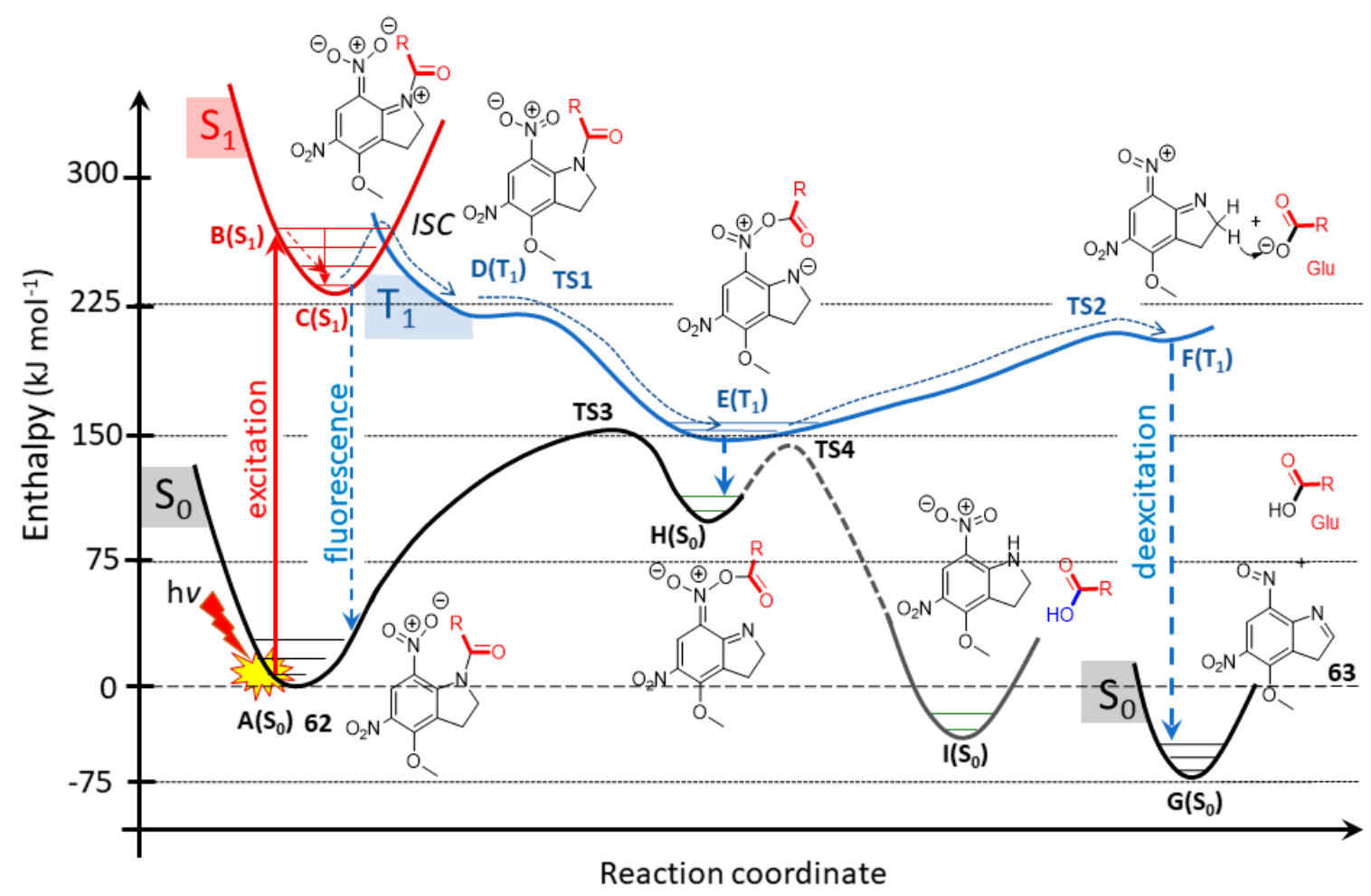

Figure 25. Quantum chemical modelling of the potential enthalpy profile of the singlet (red), triplet (blue) and ground state (black) mechanism for DNI-Glu (62) at B3LYP/6-31G(d,p)//PCM(water) level of theory. For detailed data see [138].

It is possible to explain the overall process by means of systems chemistry. Through the change in the aromaticity (AR\%) [142] and carbonylicity (CA\%) values [computed at B3LYP/6-31G(d,p)// $\operatorname{PCM}($ water $)$ it is possible to understand how the electron distribution follows the energetic changes in the triplet excited as well as the ground state during the photochemical process. DNI-Glu (62) is composed of an aromatic ring and a carbonyl group (Figure 24), characterized by values of $A R \%$ and $\mathrm{CA} \%$. During the excitation $\left[\mathrm{A}\left(\mathrm{S}_{0}\right)\right] \rightarrow\left[\mathrm{C}\left(\mathrm{S}_{1}\right)\right]$ the aromaticity is significantly reduced $(\mathrm{AR} \%$ : $86.9 \% \rightarrow 58.2 \%$ ), while the carbonylicity value remained relatively constant (CA $\%: 38.1 \% \rightarrow 40.1 \%$ ). After intersystem crossing (ISC) from singlet to triplet excited state $\left[C\left(S_{1}\right)\right] \rightarrow\left[D\left(T_{1}\right)\right]$, the molecule tries to regain its stability by slightly increasing its aromaticity (AR\%: $58.2 \% \rightarrow 66.8 \%$ ) at the expense of carbonylicity (CA\%: $40.1 \% \rightarrow 36.1 \%$ ). The reduced $C A \%$ in state $\mathrm{D}\left(\mathrm{T}_{1}\right)$ indicates that the amid group is already triggered and favors the next intramolecular rearrangement. This results in a relatively stable triplet state molecule $\mathrm{E}\left(\mathrm{T}_{1}\right)$ with an increased aromaticity $(77.8 \%)$ as well as carbonylicity $(41.8 \%)$. Subsequently, an endothermic cleavage of the $\mathrm{N}-\mathrm{O}$ bond leads to stage $\mathrm{F}\left(\mathrm{T}_{1}\right)$, then to the product $63 \mathrm{G}\left(\mathrm{S}_{0}\right)$, recovering finally both the $\mathrm{AR} \%$ and $\mathrm{CA} \%$ after a de-excitation. During the deexcitation from state $\mathrm{E}\left(\mathrm{T}_{1}\right)$ to the ground state $\mathrm{G}\left(\mathrm{S}_{0}\right)$, the rearranged molecule loses a lot of stabilization energy, represented by the sharp decreases of AR\% (21.8\%) and CA\% (31.3\%), summarized in Figure 24.

The photochemical uncaging process of DNI-Glu is an excellent example of how the electronic excitation of an aromatic moiety can activate a neighboring amide group, leading to an acyl transfer reaction.

\subsubsection{Photochemical Release of Glutamate from Coumarin-Caged Transmitters at Excited State}

The neurotransmitter derivatives of coumarin-4-yl-methyl have been developed as a new class of efficient caging scaffolds and were applied successfully to mask the biologically active amino, carbonyl [143] and hydroxyl compounds via carbamate [144-146] or carbonate [33] linkers. 
Some phosphate [56,147-155], carboxylate [56,155,156], sulfate [154], sulfonate [154] and diol [157] functionalities were also been protected by various coumarin derivatives (Figure 26) [33].

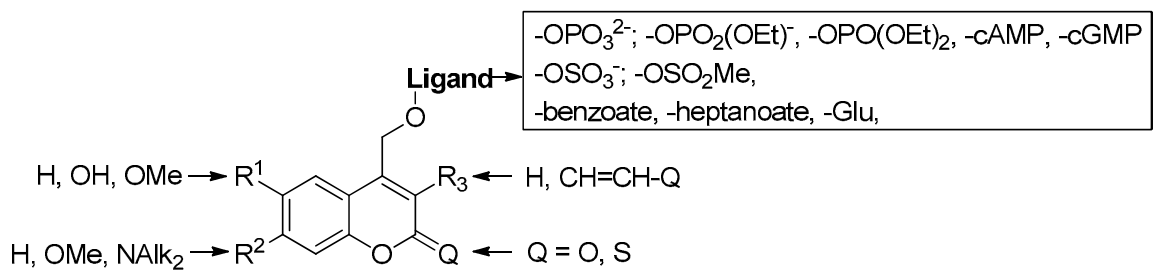

Figure 26. Some examples of cage compounds based on various coumarin scaffolds.

The photochemical mechanism of diethyl coumarin-Glu cage compound (64) has been studied and are reported here by quantum theory (Figure 27) at B3LYP/6-31G(d,p/ / PCM(water) level of theory. The mechanism and the corresponding enthalpy reaction profile are shown in Figure 28. After the absorption of photon (excitation) by the ground state of coumarin $64\left[\mathrm{~A}\left(\mathrm{~S}_{0}\right)\right]$, it reaches its excited singlet state $\mathrm{B}(\mathrm{S} 1)$. During the vibrational relaxation process at singlet excited state, the molecule reaches its lowest vibrational energy level C(S1). The molecule tends to deexcite back to its ground state $\left[\mathrm{A}\left(\mathrm{S}_{0}\right)\right]$ by means of emission (fluorescence) or non-radiative processes. However, some of the excited singlet molecule $\mathrm{C}(\mathrm{S} 1$ ) transforms to its triplet state $\mathrm{D}$ (T1) via an intersystem crossing (ISC, in Figure 28). In that $\mathrm{C}(\mathrm{S} 1)$ state, the molecule goes through a conformational change, finding the perpendicular arrangement of the side chain carbamate to the aromatic ring as the energy optimum $\mathrm{E}\left(\mathrm{T}_{1}\right)$. After a relatively high enthalpy TS $\left[34.5 \mathrm{~kJ} \mathrm{~mol}^{-1} ; \mathrm{F}\left(\mathrm{T}_{1}\right)\right]$, the $\mathrm{CH}_{2}-\mathrm{O}$ bond is cleaved heterolytically, forming a triplet state coumarin cation $\left(65,\left[\mathrm{G}\left(\mathrm{T}_{1}\right)\right]\right)$ and a ground state carbamate anion derivative $\left(66, \mathrm{~S}_{0}\right)$. The formation of the real solvent-separated ions is an energy demanding process (estimated as high as $+265.4 \mathrm{~kJ} \mathrm{~mol}^{-1}$ ), so before the ion-pair separation, the positively charged coumarin scaffold deexcites to its ground state and reacts with a water molecule immediately, resulting in coumarin alcohol [66; $\mathrm{S}_{0}(\mathrm{H})$ ]. At the same time, the carbamate derivative 66 yields the desired amino neurotransmitter (in the present cases, Me- $\mathrm{NH}_{2}$ ), while it loses $\mathrm{CO}_{2}$. Notably, the overall enthalpy change is endothermic with respect to the starting material in its $\mathrm{S}_{0}$ state, however, the reaction is greatly exothermic with respect to the reactant first excited state $S_{1}[B]$ or $S_{1}[C]$.

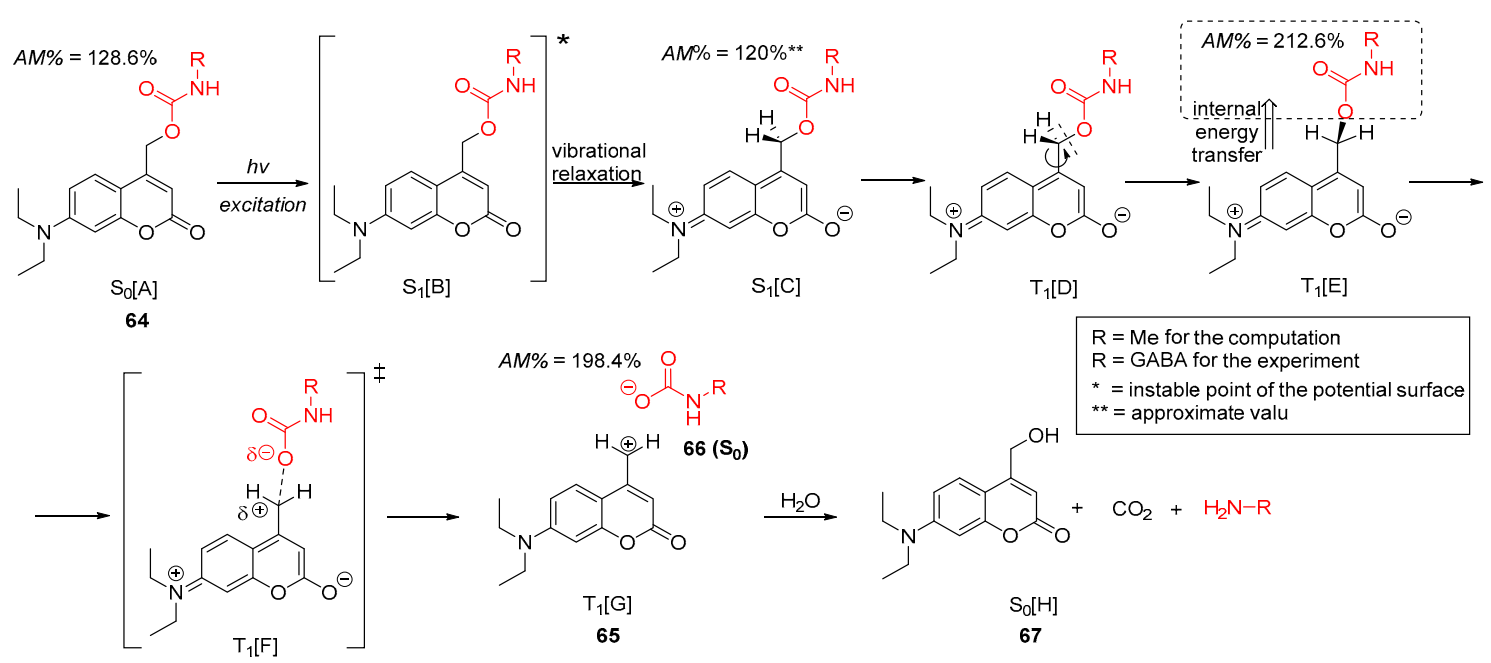

Figure 27. Mechanism of the photochemical initiated scission of coumarin-caged model compound 64 to products $66+67$ by an internal energy transfer, computed at B3LYP/6-31G(d,p)//PCM(water) level of theory. The amidicity values (AM\%) are also shown for some structures. 


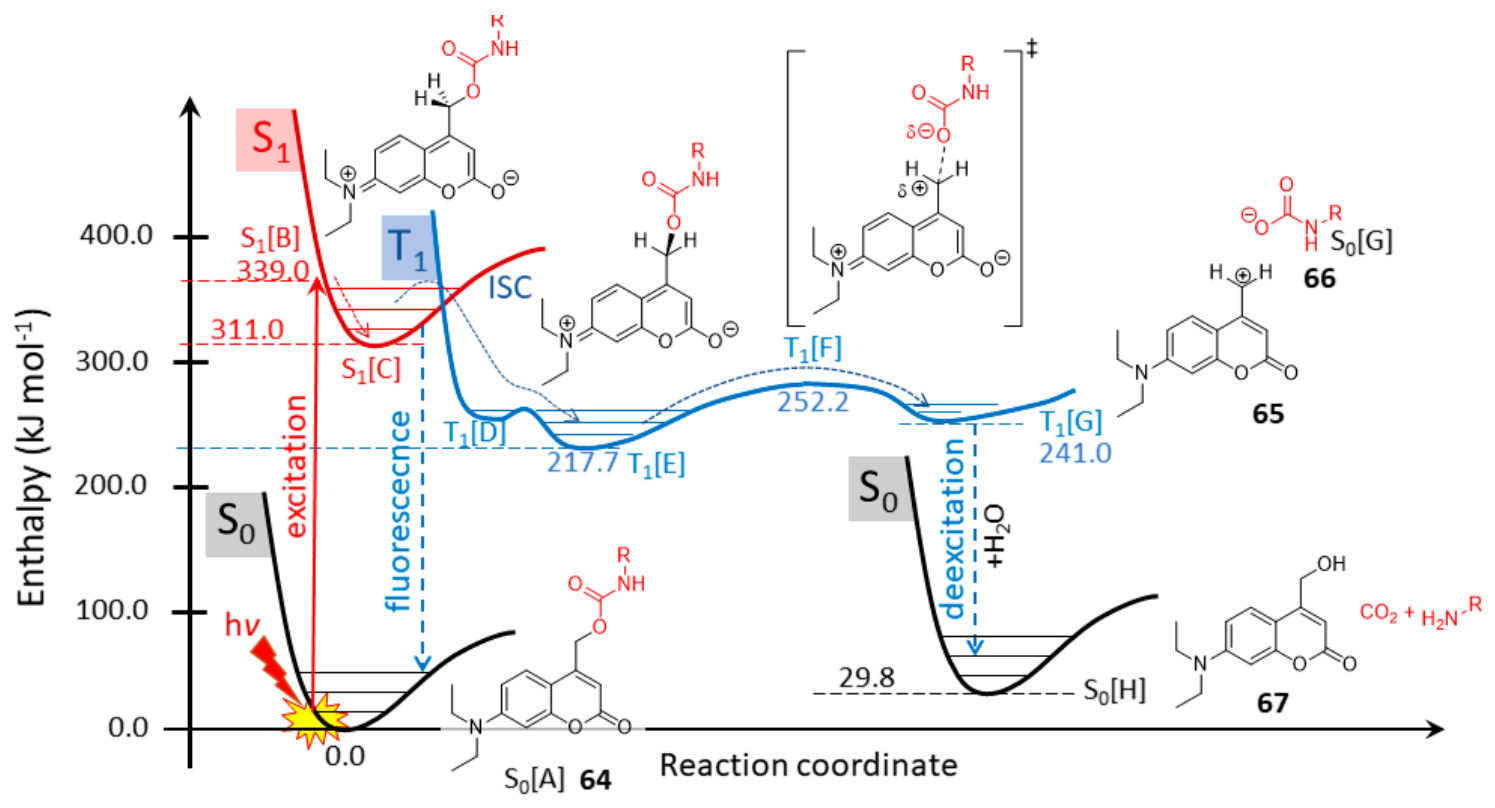

Figure 28. Reaction enthalpy $\left(H\right.$ in $\left.\mathrm{kJ} \mathrm{mol}^{-1}\right)$ profile of the photochemical initiated scission of coumarin-caged model compound 63 to $65+66$, computed at B3LYP/6-31G(d,p)//PCM(water) level of theory.

During the photochemical reaction, the original high amidicity value (AM\% $=128.6 \%)$ remains nearly constant in its $S_{1}$ state, but in its subsequent triple state $\left(T_{1}\right)$ its amidicity increased to an unprecedently high value $(212.6 \%)$, which indicates that the carbamate functionality became a good leaving group, allowing the $\mathrm{C}-\mathrm{O}$ dissociation. Finally, the forming of ground state carbamate 66 also exhibits a high value. It appears that there has been an internal energy transfer from the excited aromatic ring to the carbamate group. This means that amide, in fact, is stabilized and not activated, as might have been supposed from the study of DNI-Glu in the previous section.

\section{Materials and Methods}

All computations were carried out using the Gaussian09 program package (G09) [141]. Geometry optimizations and subsequent frequency analyses were carried out on selected amide-containing systems from which the values for the enthalpy of hydrogenation $\left(\Delta H_{\mathrm{H} 2}\right)$ were extracted. Computations were carried out at B3LYP/6-31G(d,p) level of theory [37]. Method and basis sets were chosen for their reliability in the characterization of amidicity [40] and carbonylicity [20], in agreement with works published earlier. The vibrational frequencies were computed at the same levels of theory as those used for geometry optimization, in order to properly confirm all structures as residing at minima on their potential energy hypersurfaces (PESs). In some cases, the acetonitrile or water solvent was considered by the default IEF-PCM (integral equation formalism polarizable continuum medium) method.

\section{Conclusions}

In general, amide groups have been considered to be very stable and functional for many years, due to their extensive conjugation of the $\pi$ electron system consisting of the four $\pi$ electrons. Due to this characteristic, amides can be found frequently in natural or human-made molecules as stable linkages between functioning building blocks, maintaining them for hundreds of years. During synthetic work, they are often and willingly used to inactivate a part of a given molecule as a protecting group. However, as was earlier revealed, the chemistry of the amide bond can be tricked, turning up their reactivity and forming a reactive functional group. 
In this paper we showed that there is a semi-quantitative rule to predict the outcome of an acyl transfer or transamidation reaction. This thermodynamic selection rule indicates the driving force of amide reactions based on amidicity or carbonylicity values, numerically measuring the amide bond strengths, namely the stabilization enthalpies, toward providing a simple and reliable protocol for practicing chemists. The change of amidicity or carbonylicity in the course of a reaction revealed that the process is favorable or unfavorable (Figure 29).

The amidicity-based classification of the acyl transfer reactions was demonstrated with a few case examples. Spontaneous processes suppose that the reagent amide exhibits an originally lowered amidicity value, typically by distortion or twisting. If the starting amide exhibits high amidicity it should be lowered by an amide activation. We have shown that it can be achieved by chemical activating groups or photoexcitation, to initiate the acyl exchange. Analogues activation was also used for selective amide reduction. This ON/OFF function of amides can also be revealed in natural biochemical processes, demonstrated by penicillin, blood clotting and intein-mediated protein splicing.

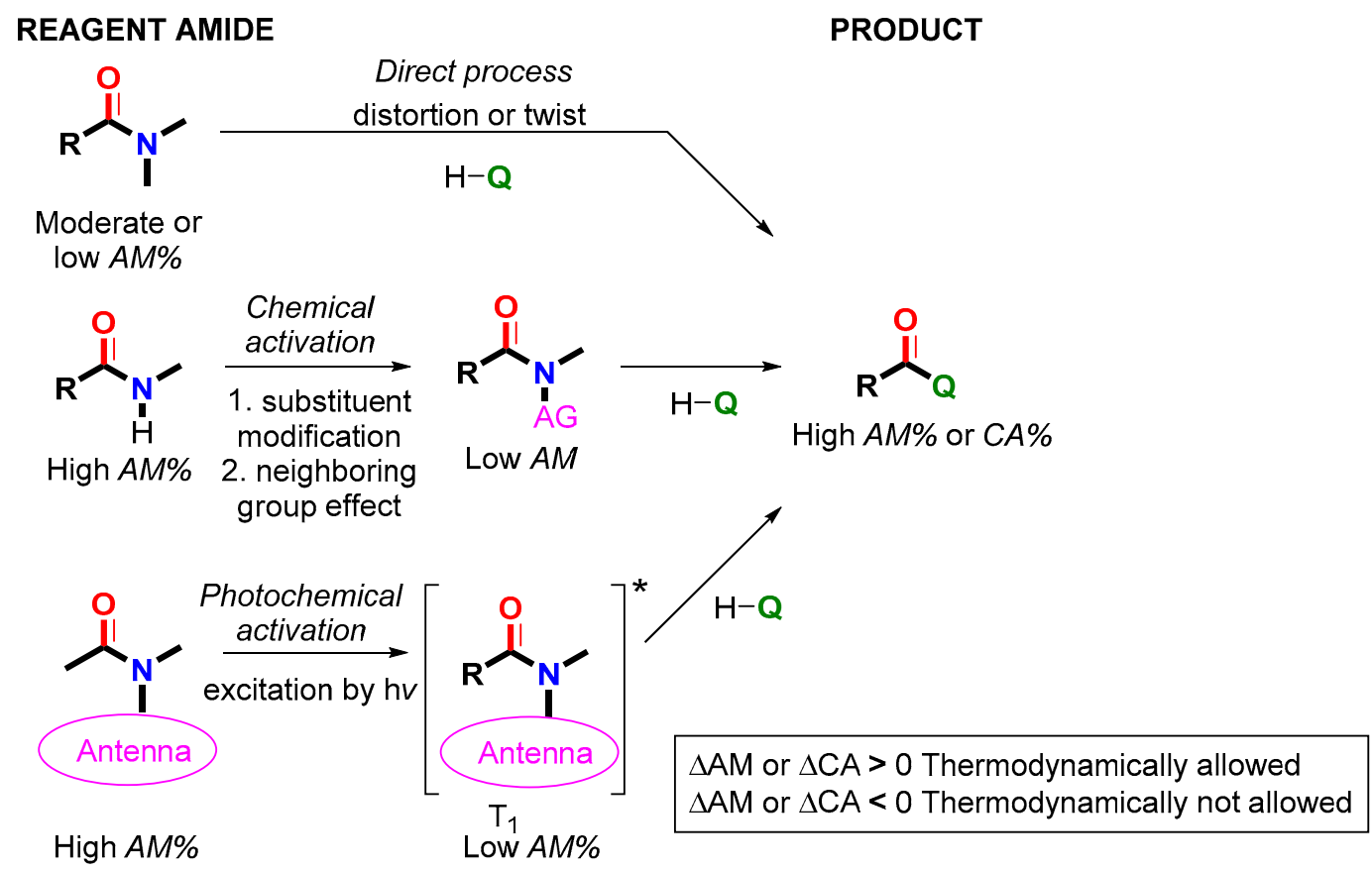

Figure 29. Summary of the amide activation processes. $\mathrm{T}_{1}=$ triplet state; $\mathrm{AM} \%=$ amidicity; $\mathrm{CA} \%=$ carbonylicity.

Author Contributions: Author Contributions: conceptualization, E.K., A.C., I.G.C. and Z.M.; methodology, Z.M.; software, Z.M.; validation, E.K., A.C. and I.G.C.; formal analysis, E.K., A.C. and I.G.C.; investigation, Z.M.; writing-original draft preparation, Z.M.; writing—review and editing E.K., A.C., I.G.C. and Z.M.; visualization A.C. and Z.M.; supervision I.G.C. and B.R.; financing B.R.; project administration, Z.M.

Funding: This project was supported by National Research, Development and Innovation Fund of Hungary, financed under the [KFI_16-1-2016-0177; NVKP_16-1-2016-0043, OTKA PD128612] funding scheme.

Conflicts of Interest: The authors declare no conflict of interest.

\section{References}

1. Pattabiraman, V.R.; Bode, J.W. Rethinking amide bond synthesis. Nature 2011, 480, 471-479. [CrossRef] [PubMed]

2. Mahesh, S.; Tang, K.; Raj, M. Amide Bond Activation of Biological Molecules Sriram. Molecules 2018, $23,2615$. [CrossRef] [PubMed]

3. Figueiredo, R.M.; Suppo, J.; Campagne, J. Nonclassical Routes for Amide Bond Formation. Chem. Rev. 2016, 116, 12029-12122. [CrossRef] [PubMed] 
4. Acosta-Guzmán, P.; Mateus-Gómez, A.; Gamba-Sánchez, D. Direct Transamidation Reactions: Mechanism and Recent Advances. Molecules 2018, 23, 2382. [CrossRef] [PubMed]

5. Valeur, E.; Bradley, M. Amide bond formation: Beyond the myth of coupling reagents. Chem. Soc. Rev. 2009, 38, 606-631. [CrossRef] [PubMed]

6. Greenberg, A.; Breneman, C.M.; Liebman, J.F. The Amide Linkage: Structural Significance in Chemistry, Biochemistry, and Materials Science; Wiley-VCH: New York, NY, USA, 2003; ISBN 978-0-471-35893-0.

7. Pauling, L.; Corey, R.B.; Branson, H.R. The structure of proteins: Two hydrogen-bonded helical configurations of the polypeptide chain. Proc. Natl. Acad. Sci. USA 1951, 37, 205-211. [CrossRef] [PubMed]

8. Hughes, A.B. (Ed.) Amino Acids, Peptides and Proteins in Organic Chemistry; Wiley-VCH: Weinheim, Germany, 2011; ISBN 978-3-527-32102-5.

9. Kaspar, A.A.; Reichert, J.M. Future directions for peptide therapeutics development. Drug Discov. Today 2013, 18, 807-817. [CrossRef] [PubMed]

10. Pauling, L. The nature of the chemical bond. Application of results obtained from the quantum mechanics and from a theory of paramagnetic susceptibility to the structure of molecules. J. Am. Chem. Soc. 1931, 53, 1367-1400. [CrossRef]

11. Pauling, L. The Nature of the Chemical Bond; Oxford University Press: London, UK, 1940.

12. Greenberg, A.; Breneman, C.M.; Liebman, J.F. (Eds.) Amide Linkage: Structural Significance in Chemistry, Biochemistry, and Materials Science; Wiley-VCH: New York, NY, USA, 2000.

13. Wiberg, K.B.; Breneman, C.M. Resonance Interactions in Acyclic Systems. 3. Formamide Internal Rotation Revisited. Charge and Energy Redistribution along the C-N Bond Rotational Pathway. J. Am. Chem. Soc. 1992, 114, 831-840. [CrossRef]

14. Glover, S.A.; Rosser, A.A. Reliable determination of amidicity in acyclic amides and lactams. J. Org. Chem. 2012, 77, 5492-5502. [CrossRef] [PubMed]

15. Van Vranken, D.; Weiss, G.A. Introduction to Bioorganic Chemistry and Chemical Biology; Garland Science (Taylor \& Francis): Oxford, UK, 2013; ISBN 978-0815342144.

16. Brix, K.; Stöcker, W. Proteases: Structure and Function; Brix, K., Stöcker, W., Eds.; Springer: Berlin, Germany, 2013; ISBN 978-3-7091-0885-7.

17. Lukes, R. Sur une nouvelle application de la règle de bredt. Collect. Czechslovak Chem. Commun. 1938, 10, 148-152. [CrossRef]

18. Woodward, R.B.; Neuberger, A.; Trenner, N.R. The Chemistry of Penicillin; Clarke, H.T., Johnson, J.R., Robinson, R., Eds.; Princeton University Press: New Jersey, NJ, USA, 1949.

19. Wasserman, H.H. Chemistry: Synthesis with a twist. Nature 2006, 441, 699-700. [CrossRef] [PubMed]

20. Mucsi, Z.; Chass, G.A.; Viskolcz, B.; Csizmadia, I.G. Quantitative scale for the extent of conjugation of carbonyl groups: "Carbonylicity" percentage as a chemical driving force. J. Phys. Chem. A 2008, 112, 9153-9165. [CrossRef] [PubMed]

21. Kemnitz, C.R.; Loewen, M.J. "Amide resonance" correlates with a breadth of C-N rotation barriers. J. Am. Chem. Soc. 2007, 129, 2521-2528. [CrossRef] [PubMed]

22. Mujika, J.I.; Matxain, J.M.; Eriksson, L.A.; Lopez, X. Resonance structures of the amide bond: The advantages of planarity. Chem.-Eur. J. 2006, 12, 7215-7224. [CrossRef] [PubMed]

23. Bechara, W.S.; Pelletier, G.; Charette, A.B. Chemoselective synthesis of ketones and ketimines by addition of organometallic reagents to secondary amides. Nat. Chem. 2012, 4, 228-234. [CrossRef] [PubMed]

24. Mujika, J.I.; Mercero, J.M.; Lopez, X. Water-promoted hydrolysis of a highly twisted amide: Rate acceleration caused by the twist of the amide bond. J. Am. Chem. Soc. 2005, 127, 4445-4453. [CrossRef] [PubMed]

25. Wang, B.; Cao, Z. Acid-catalyzed reactions of twisted amides in water solution: Competition between hydration and hydrolysis. Chem.-Eur. J. 2011, 17, 11919-11929. [CrossRef] [PubMed]

26. Cho, S.J.; Cui, C.; Lee, J.Y.; Park, J.K.; Suh, S.B.; Park, J.; Kim, B.H.; Kim, K.S. N-Protonation vs O-Protonation in Strained Amides: Ab Initio Study. J. Org. Chem. 1997, 62, 4068-4071. [CrossRef]

27. Mucsi, Z.; Tsai, A.; Szori, M.; Chass, G.A.; Viskolcz, B.; Csizmadia, I.G. A Quantitative Scale for the Extent of Conjugation of the Amide Bond. Amidity Percentage as a Chemical Driving Force. J. Phys. Chem. A 2007, 111, 13245-13254. [CrossRef] [PubMed]

28. Morgan, J.; Greenberg, A.; Liebman, J.F. Paradigms and paradoxes: O- and N-protonated amides, stabilization energy, and resonance energy. Struct. Chem. 2012, 23, 197-199. [CrossRef] 
29. Morgan, J.; Greenberg, A. Novel bridgehead bicyclic lactams: (A) Molecules predicted to have O-protonated and N-protonated tautomers of comparable stability; (B) hyperstable lactams and their O-protonated tautomers. J. Chem. Thermodyn. 2014, 73, 206-212. [CrossRef]

30. Tinnis, F.; Volkov, A.; Slagbrand, T.; Adolfsson, H. Chemoselective Reduction of Tertiary Amides under Thermal Control: Formation of either Aldehydes or Amines. Angew. Chem. Int. Ed. 2016, 55, 4562-4566. [CrossRef] [PubMed]

31. Szostak, M.; Spain, M. Highly Chemoselective Reduction of Amides (Primary, Secondary, Tertiary) to Alcohols using SmI2/Amine $/ \mathrm{H}_{2} \mathrm{O}$ under Mild Conditions. J. Am. Chem. Soc. 2014, 136, 2268-2271. [CrossRef] [PubMed]

32. Thakkar, B.; Svendsen, J.; Engh, R. Density Functional Studies on Secondary Amides: Role of Steric Factors in Cis/Trans Isomerization. Molecules 2018, 23, 2455. [CrossRef] [PubMed]

33. Klán, P.; Šolomek, T.; Bochet, C.G.; Blanc, A.; Givens, R.; Rubina, M.; Popik, V.; Kostikov, A.; Wirz, J. Photoremovable protecting groups in chemistry and biology: Reaction mechanisms and efficacy. Chem. Rev. 2013, 113, 119-191. [CrossRef] [PubMed]

34. Ellis-Davies, G.C.R. Caged compounds: Photorelease technology for control of cellular chemistry and physiology. Nat. Methods 2007, 4, 619-628. [CrossRef] [PubMed]

35. Mayer, G.; Hechel, A. Biologically active molecules with a "light switch". Angew. Chem. Int. Ed. 2006, 45, 4900-4921. [CrossRef] [PubMed]

36. Kotsuki, H.; Iwasaki, M.; Nishizawa, H. A new powerful method for the transformation of lactams into $\omega$-amino-carboxamides under high pressure conditions. Tetrahedron Lett. 1992, 33, 4945-4948. [CrossRef]

37. Becke, A.D. Density-functional thermochemistry. III. The role of exact exchange. J. Chem. Phys. 1993, 98, 5648-5652. [CrossRef]

38. Greenberg, A.; Moore, D.T.; DuBois, T.D. Small and medium-sized bridgehead bicyclic lactams: A systematic ab initio molecular orbital study. J. Am. Chem. Soc. 1996, 118, 8658-8668. [CrossRef]

39. Greenberg, A.; Venanzi, C.A. Structures and Energetics of Two Bridgehead Lactams and Their N- and O-Protonated Forms: An ab Initio Molecular Orbital Study. J. Am. Chem. Soc. 1993, 115, 6951-6957. [CrossRef]

40. Mucsi, Z.; Chass, G.A.; Csizmadia, I.G. Amidicity change as a significant driving force and thermodynamic selection rule of transamidation reactions. A synergy between experiment and theory. J. Phys. Chem. B 2008, 112, 7885-7893. [CrossRef] [PubMed]

41. Lukács, A.; Szabó, L.; Hazai, L.; Szántay, C.; Mák, M.; Gorka, Á.; Szántay, C. Seven-membered ring formation through Grewe-cyclization. Tetrahedron 2001, 57, 5843-5850. [CrossRef]

42. Sibi, M.P.; Hasegawa, H.; Ghorpade, S.R. A convenient method for the conversion of N-acyloxazolidinones to hydroxamic acids. Org. Lett. 2002, 4, 3343-3346. [CrossRef] [PubMed]

43. Galat, A.; Elion, G. The Interaction of Amides with Amines: A General Method of Acylation. J. Am. Chem. Soc. 1943, 65, 1566-1567. [CrossRef]

44. Sowa, F.J.; Nieuwland, J.A. Organic Reactions with Boron Fluoride. XIV. The Reaction of Amides with Acids and Amines. J. Am. Chem. Soc. 1937, 59, 1202-1203. [CrossRef]

45. Varga, T.R.; Nemes, P.; Mucsi, Z.; Scheiber, P. A concise synthetic pathway towards 5-substituted indolizidines. Tetrahedron Lett. 2007, 48, 1159-1161. [CrossRef]

46. Wright, W.; Brabander, H.; Hardy, R. Notes- The Rearrangement of N-(Methylaminoalkyl)anilides. J. Org. Chem. 1961, 26, 2120-2123. [CrossRef]

47. Kano, S.; Ebata, T.; Shibuya, S. Intra- and Intermolecular Nucleophilic Cleavage of the Amide Bond of b-Laactams. Chem. Pharm. Bull. 1979, 27, 2450-2455. [CrossRef]

48. Wade, P.C.; Vogt, B.R.; Toeplitz, B.; Puar, M.S.; Gougoutas, J.Z. 1,2,4-Triazolo- and 1,2,5-triazino[4,3d][1,4]benzodiazepinone ring systems: synthesis and barrier to ring inversion. J. Org. Chem. 1979, 44, 88-99. [CrossRef]

49. Kano, S.; Ebata, T.; Denta, Y.; Hibino, S.; Shibuya, S. Formtion of Some Heterocycles through Ring Transformation of 1-Arylazetidin-2-ones. Heterocycles 1977, 8, 411-416. [CrossRef]

50. Hie, L.; Fine Nathel, N.F.; Shah, T.K.; Baker, E.L.; Hong, X.; Yang, Y.F.; Liu, P.; Houk, K.N.; Garg, N.K. Conversion of amides to esters by the nickel-catalysed activation of amide C-N bonds. Nature 2015, 524, 79-83. [CrossRef] [PubMed] 
51. Itai, A.; Toriumi, Y.; Tomioka, N.; Kagechika, H.; Azumaya, I.; Shudo, K. Stereochemistry of N-methylbenzanilide and benzanilide. Tetrahedron Lett. 1989, 30, 6177-6180. [CrossRef]

52. Jin, Y.; Chen, M.; Ge, S.; Hartwig, J.F. Palladium-Catalyzed, Enantioselective $\alpha$-Arylation of $\alpha$-Fluorooxindoles. Org. Lett. 2017, 19, 1390-1393. [CrossRef] [PubMed]

53. Di Gregorio, G.; Mari, M.; Bartolucci, S.; Bartoccini, F.; Piersanti, G. Divergent reactions of oxindoles with amino alcohols: Via the borrowing hydrogen process: Oxindole ring opening vs. C3 alkylation. Org. Chem. Front. 2018, 5, 1622-1627. [CrossRef]

54. Reverdito, A.M.; Orelli, L.; Dalmaso, M.; Perillo, I.; Fernández, B.M. Synthesis and hydrolysis of substituted tetrahydropyrimidinium salts. Behaviour of the degradation products on varying pH. J. Heterocycl. Chem. 1991, 28, 273-281. [CrossRef]

55. Milos, S.; Hejtmánková, L.; Hanusek, J.; Machác, V. Synthesis and Ring Transformation of Substituted S-(1-Phenylpyrrolidine-2-ones-3-yl) isothiuronium Salts to Substituted. J. Heterocycl. Chem. 2002, 39, 1105-1107. [CrossRef]

56. Schade, B.; Hagen, V.; Schmidt, R.; Herbrich, R.; Krause, E.; Eckardt, T.; Bendig, J. Deactivation Behavior and Excited-State Properties of (Coumarin-4-yl)methyl Derivatives. 1. Photocleavage of (7-Methoxycoumarin-4-yl)methyl-Caged Acids with Fluorescence Enhancement. J. Org. Chem. 1999, 64, 9109-9117. [CrossRef]

57. Liu, C.; Szostak, M. Twisted Amides: From Obscurity to Broadly Useful Transition-Metal-Catalyzed Reactions by N-C Amide Bond Activation. Chem.-Eur. J. 2017, 23, 7157-7173. [CrossRef] [PubMed]

58. Borthwick, A.D.; Davies, D.E.; Exall, A.M.; Livermore, D.G.; Sollis, S.L.; Nerozzi, F.; Allen, M.J.; Perren, M.; Shabbir, S.S.; Woollard, P.M.; et al. 2,5-Diketopiperazines as potent, selective, and orally bioavailable oxytocin antagonists. 2. Synthesis, chirality, and pharmacokinetics. J. Med. Chem. 2005, 48, 6956-6969. [CrossRef] [PubMed]

59. Matulenko, M.A.; Lee, C.H.; Jiang, M.; Frey, R.R.; Cowart, M.D.; Bayburt, E.K.; DiDomenico, S.; Gfesser, G.A.; Gomtsyan, A.; Guo, Z.Z.; et al. 5-(3-Bromophenyl)-7-(6-morpholin-4-ylpyridin-3-yl)pyrido[2,3-d] pyrimidin4-ylamine: Structure-activity relationships of 7-substituted heteroaryl analogs as non-nucleoside adenosine kinase inhibitors. Bioorg. Med. Chem. 2005, 13, 3705-3720. [CrossRef] [PubMed]

60. Mucsi, Z.; Chass, G.A.; Ábrányi-Balogh, P.; Jójárt, B.; Fang, D.C.; Ramirez-Cuesta, A.J.; Viskolcz, B.; Csizmadia, I.G. Penicillin's catalytic mechanism revealed by inelastic neutrons and quantum chemical theory. Phys. Chem. Chem. Phys. 2013, 15, 20447-20455. [CrossRef] [PubMed]

61. Blackburn, G.M.; Skaife, C.J.; Kay, I.T. Strain effects in acyl transfer reactions. J. Chem. Res. Synopses 1980, 9 , 294-295.

62. Wang, Q.P.; Bennet, A.J.; Brown, R.S.; Santarsiero, B.D. Distorted amides as models for activated peptide $\mathrm{N}-\mathrm{C}=\mathrm{O}$ units. 2. The synthesis, hydrolytic profile, and molecular structure of 3,4-dihydro-2-oxo-1,4propanoquinoline. Can. J. Chem. 1990, 68, 1732-1739. [CrossRef]

63. Wang, Q.P.; Bennet, A.J.; Brown, R.S.; Santarsiero, B.D. Distorted Amides as Models for Activated Peptide N-C(O) Units. 3. Synthesis, Hydrolytic Profile, and Molecular Structure of 2,3,4,5-Tetrahydro-2-oxo-1,5propanobenzazepine. J. Am. Chem. Soc. 1991, 113, 5757-5765. [CrossRef]

64. Somayaji, V.; Brown, R.S. Distorted Amides as Models for Activated Peptide N-C=0 Units Produced during Enzyme-Catalyzed Acyl Transfer Reactions. 1. The Mechanism of Hydrolysis of 3,4-Dihydro-2oxo-1,4-ethanoquinoline and 2,3,4,5-Tetrahydro-2-oxo-1,5-ethanobenzazepine. J. Org. Chem. 1986, 51, 2676-2686. [CrossRef]

65. Tani, K.; Stoltz, B.M. Synthesis and structural analysis of 2-quinuclidonium tetrafluoroborate. Nature 2006, 441, 731-734. [CrossRef] [PubMed]

66. Kirby, A.J.; Komarov, I.V.; Feeder, N. Synthesis, structure and reactions of the most twisted amide. J. Chem. Soc. Perkin Trans. 2 2001, 522-529. [CrossRef]

67. Kirby, A.J.; Komarov, I.V.; Feeder, N. Spontaneous, millisecond formation of a twisted amide from the amino acid, and the crystal structure of a tetrahedral intermediate [1]. J. Am. Chem. Soc. 1998, 120, 7101-7102. [CrossRef]

68. Kirby, A.J.; Komarov, I.V.; Wothers, P.D.; Feeder, N. The Most Twisted Amide: Structure and Reactions. Angew. Chem. Int. Ed. 1998, 37, 785-786. [CrossRef]

69. Andersson, P.G.; Munslow, I.J. (Eds.) Modern Reduction Methods; Wiley-VCH: New York, NY, USA, 2008; ISBN 978-3-527-31862-9. 
70. Levkoeva, E.I.; Nikitskaya, E.S.; Yakhontov, L.N. Reaction of 2-quinuclidones with and without C-N bond breaking. Dokl. Akad. Nauk 1970, 192, 342.

71. Von Pracejus, H.; Kehlen, M.; Kehlen, H.; Matschiner, H. Neues zur sterischen mesomeriehinderung bei lactamen vom typ des $\alpha$-chinuclidons. Tetrahedron 1965, 21, 2257-2270. [CrossRef]

72. Werstiuk, N.H.; Brown, R.S.; Wang, Q. An AM1 calculational study of the protonation and reactions of 3,4-dihydro-2-oxo-1,4-ethanoquinoline, 3,4-dihydro-2-oxo-1,4-propanoquinoline, 3,3,4,5-tetrahydro-2-oxo1,5-ethanobenzazepine, 3,3,4,5-tetrahydro-2-oxo-1,5-propanobenzazepine, and N-methyl-4-b. Can. J. Chem. 1996, 74, 524-532. [CrossRef]

73. Hu, F.; Lalancette, R.; Szostak, M. Structural Characterization of N-Alkylated Twisted Amides: Consequences for Amide Bond Resonance and N-C Cleavage. Angew. Chem. Int. Ed. 2016, 55, 5062-5066. [CrossRef] [PubMed]

74. Hutchby, M.; Houlden, C.E.; Gair Ford, J.; Tyler, S.N.G.; Gagné, M.R.; Lloyd-Jones, G.C.; Booker-Milburn, K.I. Hindered ureas as masked isocyanates: Facile carbamoylation of nucleophiles under neutral conditions. Angew. Chem. Int. Ed. 2009, 48, 8721-8724. [CrossRef] [PubMed]

75. Hutchby, M.; Houlden, C.E.; Haddow, M.F.; Tyler, S.N.G.; Lloyd-Jones, G.C.; Booker-Milburn, K.I. Switching pathways: Room-temperature neutral solvolysis and substitution of amides. Angew. Chem. Int. Ed. 2012, 51, 548-551. [CrossRef] [PubMed]

76. Somayaji, V.; Skorey, K.I.; Brown, R.S. Molecular Structure of and Its Reaction with Alcohols as a Model for the Acylation Step of the Serine Proteases. J. Org. Chem. 1986, 51, 4866-4872. [CrossRef]

77. Garcia, J.; González, J.; Segura, R.; Urpí, F.; Vilarrasa, J. Reaction of N-Nitroso- and N-Nitro-N-alkylamides with Amines. J. Org. Chem. 1984, 49, 3322-3327. [CrossRef]

78. Garcia, J.; Vilarrasa, J. New synthetic "tricks" using old reagents. A mild method for the conversion of RCONHR' to RCONHR". Tetrahedron Lett. 1982, 23, 1127-1128. [CrossRef]

79. Hendrickson, J.B.; Bergeron, R. Trifumides: New Acylating Ard Triflating Reagents. Tetrahedron Lett. 1973, 14, 4607-4610. [CrossRef]

80. Bon, E.; Bigg, D.C.H.; Bertrand, G. Aluminum Chloride-Promoted Transamidation Reactions. J. Org. Chem. 1994, 59, 4035-4036. [CrossRef]

81. Shah, K.R.; Blanton, C.D.W. Reaction of Maleimides and Ethyl 3-Aminocrotonates. A Reinvestigation Leading to an Improved Synthesis of Pyrrolo[3,4-c]pyridines. J. Org. Chem. 1982, 47, 502-508. [CrossRef]

82. Davidsen, S.K.; May, P.D.; Summers, J.B. Di-tert-butyl N-Acylimidodicarbonates as Isolable Acylating Agents: Mild Conversion of Primary Carboxamides to Substituted Amides. J. Org. Chem. 1991, 56, 5482-5485. [CrossRef]

83. Shapiro, G.; Marzi, M. Facile and Selective O-Alkyl Transesterification of Primary Carbamates with Titanium(IV) Alkoxides. J. Org. Chem. 1997, 62, 7096-7097. [CrossRef] [PubMed]

84. Goodman, C.A.; Eagles, J.B.; Rudahindwa, L.; Hamaker, C.G.; Hitchcock, S.R. Synthesis, X-ray crystallography, and reactions of N-acyl and N-carbamoyl succinimides. Synth. Commun. 2013, 43, 2155-2164. [CrossRef]

85. Goodman, C.A.; Hamaker, C.G.; Hitchcock, S.R. Synthesis and evaluation of some variants of the Nefkens' reagent. Tetrahedron Lett. 2013, 54, 6012-6014. [CrossRef]

86. Ji, C.-L.; Xie, P.-P.; Hong, X. Computational Study of Mechanism and Thermodynamics of Ni/IPr-Catalyzed Amidation of Esters. Molecules 2018, 23, 2681. [CrossRef] [PubMed]

87. Li, Z.; Zhang, S.L.; Fu, Y.; Guo, Q.X.; Liu, L. Mechanism of Ni-catalyzed selective C-O bond activation in cross-coupling of aryl esters. J. Am. Chem. Soc. 2009, 131, 8815-8823. [CrossRef] [PubMed]

88. Yu, H.; Fu, Y. Mechanistic origin of cross-coupling selectivity in Ni-catalysed Tishchenko reactions. Chem.-Eur. J. 2012, 18, 16765-16773. [CrossRef] [PubMed]

89. Stach, H.; Hesse, M. Synthesis of macrocyclic compounds by ring enlargement. Tetrahedron 1988, 44, 1573-1590. [CrossRef]

90. Süsse, M.; Hájícek, J.; Hesse, M. Studies on the Carbon Zip Reaction of 2-OxocycIoalkane-l-carbonitriles. Helv. Chim. Acta 1985, 68, 1986-1997. [CrossRef]

91. Askitoglu, E.; Guggisberg, A.; Hesse, M. N-substituted 3-aminopropanenitriles and 2-aminoacetonitriles asSchiff-base equivalents. Helv. Chim. Acta 1985, 68, 750-759. [CrossRef]

92. Seyden-Penne, J. Reductions by the Alumino and Borohydrides in Organic Synthesis; Wiley-VCH: New York, NY, USA, 1997; ISBN 978-0-471-19036-3. 
93. Hudlicky, M. (Ed.) Reductions in Organic Chemistry; John Wiley \& Sons: New York, NY, USA, 1984.

94. Trost, B.M.; Fleming, I. (Eds.) Comprehensive Organic Synthesis; Pergamon: Oxford, UK, 1991.

95. Gribble, G.W. Sodium borohydride in carboxylic acid media: A phenomenal reduction system. Chem. Soc. Rev. 1998, 27, 395. [CrossRef]

96. Reeves, J.T.; Tan, Z.; Marsini, M.A.; Han, Z.S.; Xu, Y.; Reeves, D.C.; Lee, H.; Lu, B.Z.; Senanayake, C.H. A practical procedure for reduction of primary, secondary and tertiary amides to amines. Adv. Synth. Catal. 2013, 355, 47-52. [CrossRef]

97. Simmons, B.J.; Hoffmann, M.; Hwang, J.; Jackl, M.K.; Garg, N.K. Nickel-Catalyzed Reduction of Secondary and Tertiary Amides. Org. Lett. 2017, 19, 1910-1913. [CrossRef] [PubMed]

98. Ortín, I.; González, J.F.; de la Cuesta, E.; Avendaño, C. Synthesis of a novel tetrahydroisoquinoline pentacyclic framework. Tetrahedron 2009, 65, 2201-2211. [CrossRef]

99. Ortín, I.; González, J.F.; de la Cuesta, E.; Manguan-García, C.; Perona, R.; Avendaño, C. Pyrazino[1,2b]isoquinolines: Synthesis and study of their cytostatic and cytotoxic properties. Bioorganic Med. Chem. 2008, 16, 9065-9078. [CrossRef] [PubMed]

100. Valente, M.W.N.; Williams, R.M. The Concise and Versatile Synthesis of Epi-malbrancheamide and Structurally Related Analogs. Heterocycles 2006, 70, 249-259. [CrossRef]

101. Lee, B.H.; Clothier, M.F. Selective reduction of secondary amides to amines in the presence of tertiary amides. Tetrahedron Lett. 1999, 40, 643-644. [CrossRef]

102. Zein, N.; Sinha, A.M.; McGahren, W.J.; Ellestad, G.A. Calicheamicin gamma 1I: An antitumor antibiotic that cleaves double-stranded DNA site specifically. Science 1988, 240, 1198. [CrossRef] [PubMed]

103. Zein, N.; Poncin, M.; Nilakantan, R.; Ellestad, G. Calicheamicin gamma 1I and DNA: Molecular recognition process responsible for site-specificity. Science 1989, 244, 697-699. [CrossRef] [PubMed]

104. Boger, D.L.; Garbaccio, R.M. Shape-dependent catalysis: Insights into the source of catalysis for the CC-1065 and duocarmycin DNA alkylation reaction. Acc. Chem. Res. 1999, 32, 1043-1052. [CrossRef]

105. Boger, D.L.; Johnson, D.S. CC-1065 and the duocarmycins: Understanding their biological function through mechanistic studies. Angew. Chem. Int. Ed. 1996, 35, 1438-1474. [CrossRef]

106. Boger, D.L.; Boyce, C.W.; Garbaccio, R.M.; Goldberg, J.A. CC-1065 and the duocarmycins: Synthetic studies. Chem. Rev. 1997, 97, 787-828. [CrossRef] [PubMed]

107. Groll, M.; Schellenberg, B.; Bachmann, A.S.; Archer, C.R.; Huber, R.; Powell, T.K.; Lindow, S.; Kaiser, M.; Dudler, R. A plant pathogen virulence factor inhibits the eukaryotic proteasome by a novel mechanism. Nature 2008, 452, 755-758. [CrossRef] [PubMed]

108. Crawford, J.M.; Thomas, P.M.; Scheerer, J.R.; Vagstad, A.L.; Kelleher, N.L.; Townsend, C.A. Deconstruction of iterative multidomain polyketide synthase function. Science 2008, 320, 243-246. [CrossRef] [PubMed]

109. Bud, R. The fall of a wonder drug. Nature 2007, 446, 981. [CrossRef]

110. Palta, S.; Saroa, R.; Palta, A. Overview of the coagulation system. Indian J. Anaesth. 2014, 58, 515-523. [CrossRef] [PubMed]

111. Adams, R.L.C.; Bird, R.J. Review article: Coagulation cascade and therapeutics update: Relevance to nephrology. Part 1: Overview of coagulation, thrombophilias and history of anticoagulants. Nephrology 2009, 14, 462-470. [CrossRef] [PubMed]

112. Hoffman, R.; Benz, E.; Shattil, S.; Furie, B.; Cohen, H. (Eds.) Hematology: Basic Principles and Practice, 4th ed.; Elsevier: Philadelphia, PA, USA, 2005; ISBN 978-0443079542.

113. Griffin, M.; Casadio, R.; Bergamini, C.M. Transglutaminases: Nature's biological glues. Biochem. J. 2002, 368, 377-396. [CrossRef] [PubMed]

114. Kane, P.; Yamashiro, C.; Wolczyk, D.; Neff, N.; Goebi, M.; Stevens, T. Protein splicing converts the yeast TFP1 gene product to the 69-kD subunit of the vacuolar $\mathrm{H}(+)$-adenosine triphosphatase. Science 1990, 250, 651-657. [CrossRef] [PubMed]

115. Anraku, Y.; Mizutani, R.; Satow, Y. Protein splicing: Its discovery and structural insight into novel chemical mechanisms. IUBMB Life 2005, 57, 563-574. [CrossRef] [PubMed]

116. Hirata, R.; Ohsumi, Y.; Nakano, A.; Kawasaki, H.; Suzuki, K.; Anraku, Y. Molecular Structure of a Gene, VMA1, Encoding the Catalytic Subunit of $\mathrm{H}+$-Translocating Adenosine Triphosphatase from Vacuolar Membranes of Saccharomyces cerevisiae. J. Biol.Chem. 1990, 265, 6726-6733. [PubMed]

117. Gimble, F.S.; Thorner, J. Homing of a DNA endonuclease gene by meiotic gene conversion in Saccharomyces cerevisiae. Nature 1992, 357, 301-306. [CrossRef] [PubMed] 
118. Kawasaki, M.; Makino, S.I.; Matsuzawa, H.; Satow, Y.; Ohya, Y.; Anraku, Y. Folding-dependent in vitro protein splicing of the Saccharomyces cerevisiae VMA1 protozyme. Biochem. Biophys. Res. Commun. 1996, 222, 827-832. [CrossRef] [PubMed]

119. Kawasaki, M.; Nogami, S.; Satow, Y.; Ohya, Y.; Anraku, Y. Identification of three core regions essential for protein splicing of the yeast Vma1 protozyme. A random mutagenesis study of the entire VMA1- derived endonuclease sequence. J. Biol. Chem. 1997, 272, 15668-15674. [CrossRef] [PubMed]

120. Kawasaki, M.; Satow, Y.; Ohya, Y.; Anraku, Y. Protein splicing in the yeast Vma1 protozyme: Evidence for an intramolecular reaction. FEBS Lett. 1997, 412, 518-520. [CrossRef]

121. Walsh, C. Molecular mechanisms that confer antibacterial drug resistance. Nature 2000, 406, 775. [CrossRef] [PubMed]

122. Dennis, C. The bugs of war. Nature 2001, 411, 232. [CrossRef] [PubMed]

123. Theilgaard, H.B.A.; Kristiansen, K.N.; Henriksen, C.M.; Nielsen, J. Purification and characterization of delta-(L-alpha-aminoadipyl)-L-cysteinyl-D-valine synthetase from Penicillium chrysogenum. Biochem. J. 1997, 327, 185-191. [CrossRef] [PubMed]

124. Huffman, G.W.; Gesellchen, P.D.; Turner, J.R.; Rothenberger, R.B.; Osborne, H.E.; Miller, F.D.; Chapman, J.L.; Queener, S.W. Substrate Specificity of Isopenicillin N Synthase. J. Med. Chem. 1992, 35, 1897-1914. [CrossRef] [PubMed]

125. Roach, P.L.; Clifton, I.J.; Fülöp, V.; Harlos, K.; Barton, G.J.; Hajdu, J.; Andersson, I.; Schofield, C.J.; Baldwin, J.E. Crystal structure of isopenicillin $\mathrm{N}$ synthase is the first from a new structural family of enzymes. Nature 1995, 375, 700. [CrossRef] [PubMed]

126. Voet, D.; Voet, J.G. Biochemistry, 3rd ed.; John Wiley \& Sons, Inc.: Hoboken, NJ, USA, 2004.

127. Cohen, M.L. Changing patterns of infectious disease. Nature 2000, 406, 762. [CrossRef] [PubMed]

128. Smaglik, P. Antibiotic resistance must be monitored, US Senate is told. Nature 2000, 407, 437. [CrossRef] [PubMed]

129. Nogrady, T. Medicinal Chemistry A Biochemical Approach; Oxford University Press: New York, NY, USA, 1985.

130. Sheehan, J.C. The enchanted Ring: The Untold Story of Penicillin; The MIT Press: Cambridge, MA, USA, 1982; ISBN 9780262192040.

131. Johnson, J.R.; Woodward, R.B.; Robinson, R. The Chemistry of Penicillin; Clarke, H.T., Ed.; Princton University Press: Princton, NJ, USA, 1949; ISBN 9780691627489.

132. Woodward, R.B. Recent advances in the chemistry of natural products. Science 1966, 153, 487-493. [CrossRef] [PubMed]

133. Newton, G.; Abraham, E.P. Cephalosporin C, a New Antibiotic containing Sulphur and D- $\alpha$-Aminoadipic Acid. Nature 1955, 175, 548. [CrossRef] [PubMed]

134. Tally, F.P.; Jacobus, N.V.; Gorbach, S.L. In vitro activity of thienamycin. Antimicrob. Agents Chemother. 1978, 14, 436-438. [CrossRef] [PubMed]

135. Johnston, D.B.R.; Schmitt, S.M.; Bouffard, F.A.; Christensen, B.G. Total Synthesis of ( \pm )-Thienamycin. J. Am. Chem. Soc. 1978, 100, 313-315. [CrossRef]

136. Araya, R. Input transformation by dendritic spines of pyramidal neurons. Front. Neuroanat. 2014, 8, 1-18. [CrossRef] [PubMed]

137. Granger, A.J.; Nicoll, R.A. Expression mechanisms underlying long-term potentiation: A postsynaptic view, 10 years on. Philos. Trans. R. Soc. Lond. B Biol. Sci. 2014, 369, 1-6. [CrossRef]

138. Pálfi, D.; Chiovini, B.; Szalay, G.; Kaszás, A.; Turi, G.F.; Katona, G.; Ábrányi-Balogh, P.; Szori, M.; Potor, A.; Frigyesi, O.; et al. High efficiency two-photon uncaging coupled by the correction of spontaneous hydrolysis. Org. Biomol. Chem. 2018, 16, 1958-1970. [CrossRef] [PubMed]

139. Papageorgiou, G.; Ogden, D.; Kelly, G.; Corrie, J.E.T. Synthetic and photochemical studies of substituted 1-acyl-7-nitroindolines. Photochem. Photobiol. Sci. 2005, 4, 887-896. [CrossRef] [PubMed]

140. Warther, D.; Gug, S.; Specht, A.; Bolze, F.; Nicoud, J.F.; Mourot, A.; Goeldner, M. Two-photon uncaging: New prospects in neuroscience and cellular biology. Bioorg. Med. Chem. 2010, 18, 7753-7758. [CrossRef] [PubMed]

141. Frisch, M.J.; Trucks, G.W.; Schlegel, H.B.; Scuseria, G.E.; Robb, M.A.; Cheeseman, J.R.; Scalmani, G.; Barone, V.; Mennucci, B.; Petersson, G.A.; et al. Gaussian 09, Revision D.01; Gaussian, Inc.: Wallingford, CT, USA, 2009. 
142. Kovács, E.; Sághy, P.; Turczel, G.; Tóth, I.; Lendvay, G.; Domján, A.; Anastas, P.T.; Tuba, R. Metathesis of renewable polyene feedstocks-Indirect evidences of the formation of catalytically active ruthenium allylidene species. J. Organomet. Chem. 2017, 847, 213-217. [CrossRef]

143. Lu, M.; Fedoryak, O.D.; Moister, B.R.; Dore, T.M. Bhc-diol as a photolabile protecting group for aldehydes and ketones. Org. Lett. 2003, 5, 2119-2122. [CrossRef] [PubMed]

144. Montgomery, H.J.; Perdicakis, B.; Fishlock, D.; Lajoie, G.A.; Jervis, E.; Guy Guillemette, J. Photo-control of nitric oxide synthase activity using a caged isoform specific inhibitor. Bioorg. Med. Chem. 2002, 10, 1919-1927. [CrossRef]

145. Takaoka, K.; Tatsu, Y.; Yumoto, N.; Nakajima, T.; Shimamoto, K. Synthesis and photoreactivity of caged blockers for glutamate transporters. Bioorg. Med. Chem. Lett. 2003, 13, 965-970. [CrossRef]

146. Takaoka, K.; Tatsu, Y.; Yumoto, N.; Nakajima, T.; Shimamoto, K. Synthesis of carbamate-type caged derivatives of a novel glutamate transporter blocker. Bioorg. Med. Chem. 2004, 12, 3687-3694. [CrossRef] [PubMed]

147. Givens, R.S.; Matuszewski, B. Photochemistry of Phosphate Esters: An Efficient Method for the Generation of Electrophiles1. J. Am. Chem. Soc. 1984, 106, 6860-6861. [CrossRef]

148. Furata, T.; Torigai, H.; Sugimoto, M.; Iwamura, M. Photochemical Properties of New Photolabile cAMP Derivatives in a Physiological Saline Solution. J. Org. Chem. 1995, 60, 3953-3956. [CrossRef]

149. Hagen, V.; Bendig, J.; Frings, S.; Wiesner, B.; Schade, B.; Helm, S.; Lorenz, D.; Benjamin Kaupp, U. Synthesis, photochemistry and application of (7-methoxycoumarin-4-yl)methyl-caged 8-bromoadenosine cyclic 3',5'-monophosphate and 8-bromoguanosine cyclic 3',5'-monophosphate photolyzed in the nanosecond time region. J. Photochem. Photobiol. B Biol. 1999, 53, 91-102. [CrossRef]

150. Eckardt, T.; Hagen, V.; Schade, B.; Schmidt, R.; Schweitzer, C.; Bendig, J. Deactivation behavior and excited-state properties of (coumarin-4-yl)methyl derivatives. 2. Photocleavage of selected (coumarin-4yl)methyl-caged adenosine cyclic 3',5'-monophosphates with fluorescence enhancement. J. Org. Chem. 2002, 67, 703-710. [CrossRef] [PubMed]

151. Geißler, D.; Kresse, W.; Wiesner, B.; Bendig, J.; Kettenmann, H.; Hagen, V. DMACM-caged adenosine nucleotides: Ultrafast phototriggers for ATP, ADP, and AMP activated by long-wavelength irradiation. ChemBioChem 2003, 4, 162-170. [CrossRef] [PubMed]

152. Hagen, V.; Frings, S.; Wiesner, B.; Helm, S.; Kaupp, U.B.; Bendig, J. [7-(Dialkylamino)coumarin-4yl]methyl-caged compounds as ultrafast and effective long-wavelength phototriggers of 8-bromo-substituted cyclic nucleotides. ChemBioChem 2003, 4, 434-442. [CrossRef] [PubMed]

153. Furuta, T.; Takeuchi, H.; Isozaki, M.; Takahashi, Y.; Kanehara, M.; Sugimoto, M.; Watanabe, T.; Noguchi, K.; Dore, T.M.; Kurahashi, T.; et al. Bhc-cNMPs as either water-soluble or membrane-permeant photoreleasable cyclic nucleotides for both one- and two-photon excitation. ChemBioChem 2004, 5, 1119-1128. [CrossRef] [PubMed]

154. Geißler, D.; Antonenko, Y.N.; Schmidt, R.; Keller, S.; Krylova, O.O.; Wiesner, B.; Bendig, J.; Pohl, P.; Hagen, V. (Coumarin-4-yl)methyl esters as highly efficient, ultrafast phototriggers for protons and their application to acidifying membrane surfaces. Angew. Chem. Int. Ed. 2005, 44, 1195-1198. [CrossRef] [PubMed]

155. Hagen, V.; Dekowski, B.; Nache, V.; Schmidt, R.; Geißler, D.; Lorenz, D.; Eichhorst, J.; Keller, S.; Kaneko, H.; Benndorf, K.; Wiesner, B. Coumarinylmethyl esters for ultrafast release of high concentrations of cyclic nucleotides upon one- and two-photon photolysis. Angew. Chem. Int. Ed. 2005, 44, 7887-7891. [CrossRef] [PubMed]

156. Furuta, T.; Wang, S.S.-H.; Dantzker, J.L.; Dore, T.M.; Bybee, W.J.; Callaway, E.M.; Denk, W.; Tsien, R.Y. Brominated 7-hydroxycoumarin-4-ylmethyls: Photolabile protecting groups with biologically useful cross-sections for two photon photolysis. Proc. Natl. Acad. Sci. USA 1999, 96, 1193-1200. [CrossRef] [PubMed]

157. Lin, W.; Lawrence, D.S. A strategy for the construction of caged diols using a photolabile protecting group. J. Org. Chem. 2002, 67, 2723-2726. [CrossRef] [PubMed]

(C) 2018 by the authors. Licensee MDPI, Basel, Switzerland. This article is an open access article distributed under the terms and conditions of the Creative Commons Attribution (CC BY) license (http://creativecommons.org/licenses/by/4.0/). 